\title{
Nanotheranostics
}

2021; 5(1): 90-112. doi: $10.7150 /$ ntno. 50860

Review

\section{Noninvasive Imaging of Cancer Immunotherapy}

\author{
Omar Abousaway ${ }^{1^{*}}$, Taha Rakhshandehroo ${ }^{*}$, Annick D. Van den Abbeele ${ }^{1,2}$, Moritz F. Kircher ${ }^{1,2}$, \\ Mohammad Rashidian ${ }^{1 凶}$ \\ 1. Department of Imaging, Dana-Farber Cancer Institute and Harvard Medical School, Boston, MA, 02215, USA. \\ 2. Department of Radiology, Brigham and Women's Hospital and Harvard Medical School, Boston, MA, 02215, USA. \\ *These authors contributed equally to this work. \\ \# In memory of Moritz F. Kircher. \\ $\bowtie$ Corresponding author: Mohammad Rashidian, PhD, E-mail: mohammad_rashidian@dfci.harvard.edu. \\ (c) The author(s). This is an open access article distributed under the terms of the Creative Commons Attribution License (https://creativecommons.org/licenses/by/4.0/). \\ See http://ivyspring.com/terms for full terms and conditions.
}

Received: 2020.07.19; Accepted: 2020.10.19; Published: 2021.01.01

\begin{abstract}
Immunotherapy has revolutionized the treatment of several malignancies. Notwithstanding the encouraging results, many patients do not respond to treatments. Evaluation of the efficacy of treatments is challenging and robust methods to predict the response to treatment are not yet available. The outcome of immunotherapy results from changes that treatment evokes in the tumor immune landscape. Therefore, a better understanding of the dynamics of immune cells that infiltrate into the tumor microenvironment may fundamentally help in addressing this challenge and provide tools to assess or even predict the response. Noninvasive imaging approaches, such as PET and SPECT that provide whole-body images are currently seen as the most promising tools that can shed light on the events happening in tumors in response to treatment. Such tools can provide critical information that can be used to make informed clinical decisions. Here, we review recent developments in the field of noninvasive cancer imaging with a focus on immunotherapeutics and nuclear imaging technologies and will discuss how the field can move forward to address the challenges that remain unresolved.
\end{abstract}

Key words: Noninvasive Imaging, Cancer Immunotherapy

\section{Introduction}

Immunotherapy has revolutionized cancer treatment. Antibodies against immune checkpoint molecules such as programmed cell death protein 1 (PD-1) and its ligand PD-L1, and the cytotoxic lymphocyte antigen-4 (CTLA-4), temporarily blocks inhibitory signals of $\mathrm{T}$ cells, thereby strengthening activation of anti-tumor $\mathrm{T}$ cell responses [1,2]. Checkpoint blockade treatments have resulted in durable responses in many cancers including melanoma and non-small cell lung cancer, among others [3,4]. Adoptive cell therapy (ACT) has, likewise, showed great promise in the treatment of several malignancies, especially blood-born cancers [5]. ACT uses expanded tumor infiltrating lymphocytes or engineered immune cells to induce an anti-tumor response [6,7]. Initially, ACT involved $e x$ vivo expansion of patients' tumor-infiltratinglymphocytes (TILs) followed by reinfusion of expanded TILs [8]. Later efforts have centered on engineering patient $\mathrm{T}$ cells to express a $\mathrm{T}$ cell receptor (TCR) or chimeric antigen receptor (CAR) that utilizes an antibody fragment, such as a single chain variable fragment $(\mathrm{scFv})$, targeted to cancer specific markers. Cancer specific markers that have been targeted using CARs include CD19 and B cell maturation antigen (BCMA) on B cell malignancies, prostate specific membrane antigen (PSMA), and mesothelin [9,10]. Recent preclinical and clinical efforts have successfully adapted ACT technology to other immune cells including Natural Killer cells (NK) and macrophages [11,12].

Notwithstanding the encouraging results, patient response to immunotherapy has been heterogeneous: while some patients show durable response, many patients only experience a partial or no response [13]. Some patients also face serious 
immune-related adverse events (irAEs) such as dermatitis, colitis, endocrinopathies, hepatitis, pneumonitis, myocarditis and others which can be severe or even fatal $[14,15]$. Therefore, stratifying patients with predictive markers prior to immunotherapy can potentially identify patients who will most likely respond to therapy, and avoid unnecessary toxicity in patients who are unlikely to respond. For example, it has been shown that the infiltration of $\mathrm{T}$ cells in the tumor microenvironment (TME) as well as the activation status of such $\mathrm{T}$ cells correlates with treatment outcome $[16,17]$. Therefore, monitoring infiltration of $\mathrm{T}$ cells in patients holds predictive value. The gold-standard to predict response to treatment remains immunohistochemical staining of tumor biopsies. However, biopsies are invasive, prone to sampling errors, and single-tumor biopsy specimens may not reflect the immune response in the entire tumor burden due to extensive intra- and inter-tumor heterogeneity $[18,19]$. Some lesions are not even accessible for biopsies [20], and, for obvious reasons, the number of lesions that can be biopsied in a patient in one session in a safe and reasonable manner is also limited. The fact that not every metastasis can be biopsied and combined with the knowledge that every metastases may harbor information crucial to designing the optimal treatment regimen, this illustrates the great need for more advanced imaging methods that can provide this information in an entirely noninvasive fashion.

Noninvasive functional whole-body imaging approaches, such as positron emission tomography (PET) and single-photon emission computed tomography (SPECT), combined as hybrid systems with computed tomography (CT) or magnetic resonance imaging (MRI) as PET/CT or PET/MRI are suitable for addressing this pressing need. PET relies on the detection of positrons emitted by radioisotopes, while SPECT relies on the detection of gamma particles. The most commonly used radiotracer is ${ }^{18} \mathrm{~F}$-fluoro-2-deoxyglucose $\left({ }^{18} \mathrm{~F}\right.$-FDG), which is taken up by rapidly proliferating glucose-avid cancer cells and is used to detect primary and metastatic cancer lesions [21]. However, ${ }^{18}$ F-FDG uptake is not tumor cell-specific as activated immune cells can also uptake ${ }^{18}$ F-FDG [22]. Furthermore, tumors can be heterogeneous, and have distinct profile of infiltrating immune cells and cytokines. Therefore, to evaluate the response to immunotherapy, imaging strategies are needed to specifically image different subsets of immune cells and secreted factors. Numerous methods have been developed to address this issue. One approach is a method referred to as "immunoPET", in which an antibody that targets a cell-surface marker specific for a cell type is radiolabeled with a
PET isotope and used to track the dynamics of the targeted cells [23-25]. The two common approaches used to image engineered T cells are ex vivo labeling of the cells with radioisotopes or the use of reporter genes that bind to targeted radiolabeled tracers $[26,27]$. PET imaging through the use of radiolabeled cytokines and cytokine targeted antibodies such as IFN- $\gamma$ in the TME has also shown promise as a tool to assess progress of immunotherapy in preclinical models [28]. As the repertoire of immunotherapeutics expands rapidly, there is a great need to develop the tools to monitor, assess and even predict the response to these treatments. In this article, we will review the recent developments towards noninvasive wholebody imaging approaches to characterize tumors and assess the response to cancer immunotherapy.

\section{Small molecules for imaging immune responses}

Radiolabeled small molecules comprise the largest group of PET tracers and are the most widely used for clinical PET scans [29]. These tracers are based on drugs or metabolites with specificity for a desired cell type or metabolic process. Examples of such tracers include radiolabeled sugars, nucleosides, hormones, and small molecule drugs. These tracers are unique in their capacity to be transported through cell membranes to access intracellular protein targets, and thus enable targeting of a larger number of proteins. By virtue of their small size, small molecule tracers show faster clearance from circulation and higher tissue penetration relative to antibody-based tracers. Consequently, images can be acquired within minutes to hours after tracer administration.

Despite the favorable characteristics of small molecule tracers, there is difficulty in using them to assess the immune response to cancer. Because of the rapid metabolism and excretion of such tracers, there is typically high off-target uptake in the kidneys and bladder. Additionally, the most commonly used metabolism-based tracers cannot distinguish between activated immune cells and cancer cells. One such tracer, ${ }^{18} \mathrm{~F}-\mathrm{FDG}$, is an analog of glucose commonly used for cancer detection and diagnosis [30,31]. ${ }^{18} \mathrm{~F}-\mathrm{FDG}$ is also commonly used in patients receiving immunotherapy because of its ability to assess temporal changes in the entire tumor burden and its potential ability to diagnose immune related adverse events (irAEs) before they become symptomatic [32]. ${ }^{18} \mathrm{~F}-\mathrm{FDG}$ is taken up by metabolically active cells expressing the GLUT1 and/or GLUT3 transporters, which included both activated immune cells and cancer cells, as well as other glucose-avid cells such as the brain and heart [33-35]. As such, ${ }^{18}$ F-FDG PET is unable to distinguish activated immune cells from 
cancer cells. Another example of a commonly used metabolism-based tracer for cancer diagnosis and detection is ${ }^{18} \mathrm{~F}$-fluorothymidine (FLT) [36,37]. ${ }^{18} \mathrm{~F}-\mathrm{FLT}$ is an analog of thymidine and is phosphorylated by the enzyme Thymidine Kinase 1 (TK1). TK1 plays a key role in DNA replication and is highly expressed during the $S$ phase of the cell cycle. Uptake of ${ }^{18} \mathrm{~F}-\mathrm{FLT}$ reflects TK1 activity and cellular proliferation [36]. Because ${ }^{18} \mathrm{~F}-\mathrm{FDG}$ and ${ }^{18} \mathrm{~F}-\mathrm{FLT}$ do not show selective uptake in immune cells, they are not suitable tracers for assessing the immune cells involved in the response to therapy with high specificity.

Recently developed metabolism-based tracers take advantage of the metabolic pathways upregulated in immune cells to provide an immune cell-specific PET signal. While most tissues rely on the de novo DNA synthesis pathway, rapidly proliferating immune cells utilize the nucleoside salvage pathway for DNA synthesis [38]. Deoxycytidine kinase (dCK) is the rate-limiting enzyme in the nucleoside salvage pathway, and is highly expressed in lymphocytes [39]. Targeting dCK using radiolabeled small molecules is a strategy that has been used to selectively image immune cells (Figure 1A). ${ }^{18} \mathrm{~F}-\mathrm{FAC}$ \{1-(2'-deoxy-2'$\left[{ }^{18} \mathrm{~F}\right]$ fluoroarabinofuranosyl) cytosine $\}$ is a nucleoside analog that was identified by screening for molecules that show high retention in proliferating CD8+ T cells [40]. During in vivo PET scans, ${ }^{18}$ F-FAC showed high signal-to-background in lymphoid organs as well as nonspecific uptake in the bone marrow and gastrointestinal tract. Ex vivo analysis revealed ${ }^{18} \mathrm{~F}-\mathrm{FAC}$ labels $\mathrm{T}$ cells, B cells, and $\mathrm{CD} 11 \mathrm{~b}^{+}$myeloid cells. In an oncoretrovirus tumor model, imaging with ${ }^{18} \mathrm{~F}-\mathrm{FAC}$ showed high uptake in the tumor, tumor draining lymph nodes, and lymphoid organs [40]. Because, ${ }^{18} \mathrm{~F}-\mathrm{FAC}$ is rapidly catabolized by cytidine deaminase, it is likely not a suitable imaging tool for ultimate clinical translation [41]. ${ }^{18} \mathrm{~F}-\mathrm{CFA}$ (2-chloro-2' deoxy-2'-[18F]fluoro-9-b-D-arabinofuranosyl-adenine ) is a PET tracer designed to address this issue [42]. ${ }^{18} \mathrm{~F}-\mathrm{CF}$ is also a substrate of $\mathrm{dCK}$ but is not catabolized by cytidine deaminase (Figure 1B) [42]. In healthy patients, ${ }^{18} \mathrm{~F}-\mathrm{CFA}$ shows high uptake in the lymphoid organs, as well as the liver and bone marrow (Figure 1C) [42]. In a clinical study, ${ }^{18} \mathrm{~F}-\mathrm{CFA}$ was used to assess the immune response to immunotherapy in glioblastoma multiforme (GBM) patients. After treatment with pembrolizumab and a dendritic cell vaccine, GBM patients showed increased uptake in the tumors as well as the secondary lymphoid organs. Importantly, uptake in the tumor correlated with the concentration of TILs [43]. In an ongoing clinical trial, ${ }^{18}$ F-CFA is being used to assess the immune response to anti-PD-1 therapy in melanoma patients (NCT03409419). 9-( $\beta$-D-Arabino- furanosyl)guanine (AraG) is a guanosine analog with selective toxicity to $\mathrm{T}$ lymphocytes. Nelarabine is a prodrug of AraG that is used to treat T-cell acute lymphoblastic leukemia and T-cell lymphoblastic lymphoma [44]. ${ }^{18} \mathrm{~F}-\mathrm{F}-\mathrm{AraG}$ was developed to selectively image $\mathrm{T}$ cells in vivo [45]. Importantly, ${ }^{18} \mathrm{~F}-\mathrm{F}-\mathrm{AraG}$ does not result in toxicity to T cells in vitro [46]. In a murine model of colorectal cancer ${ }^{18} \mathrm{~F}-\mathrm{F}-\mathrm{AraG}$ PET was able to successfully predict the response to anti-PD-1 therapy 48 hours after administration of anti-PD-1 therapy, responding mice showed a significantly higher PET signal in their tumors relative to non-responding mice [46]. In a model of acute graft-versus-host disease, ${ }^{18} \mathrm{~F}-\mathrm{F}-\mathrm{AraG}$ showed high uptake in the secondary lymphoid organs prior to the manifestations of clinical symptoms. Uptake was also observed in the heart, spleen, and liver [47]. In one of several ongoing clinical trials, ${ }^{18}$ F-F-AraG PET is being used to assess the response to checkpoint blockade therapy for patients with solid tumors (NCT03802123). In another clinical trial, ${ }^{18} \mathrm{~F}-\mathrm{F}-\mathrm{AraG}$ PET will be used to detect $\mathrm{T}$ cell activation in non-small cell lung cancer patients undergoing PD-1/PD-L1-directed therapy (NCT04186988).

The kynurenine pathway of tryptophan metabolism contributes to an immunosuppressive TME and has been a target for imaging. Tryptophan metabolites induce $\mathrm{T}$ cell apoptosis and upregulate the differentiation of Tregs in vitro $[48,49]$. Macrophages and cancer cells express the enzyme indoleamine 2,3-dioxygenase (IDO) which metabolizes tryptophan to kynurenine [50]. Expression of IDO is associated with poor clinical outcomes and increased cancer metastasis [51]. 1-(2-18 F-fluoroethyl)-L-tryptophan (1-L-18 F-FETrp) is a PET tracer developed to monitor IDO-mediated tryptophan metabolism in vivo [52]. In a preclinical mammary cancer model, 1-L-18F-FETrp showed high uptake in the tumor, by virtue of binding to IDO [52]. This suggests that 1-L-18F-FETrp is a useful tool for assessing tryptophan metabolism in vivo, and may be helpful to assess the tumor immune landscape.

Small molecules that bind to markers of $\mathrm{T}$ cell activation can also be radiolabeled and used to assess the immune response to cancer. A ${ }^{68} \mathrm{Ga}$-radiolabeled granzyme B-binding peptide has been used to assess the response to checkpoint blockade [53]. In a colorectal cancer model, mice were treated with both anti-CTLA-4 and anti-PD-1 antibodies and imaged 1 hour post-injection of the tracer. Mice that responded to treatment showed high uptake in the tumor, while non-responders showed low tumor uptake [53].

Small molecule tracers with specificity for immune cells have shown promise for predicting the 
response to immunotherapy. Small molecule tracers binding to immune cell markers such as CD8, CD4, $\mathrm{CD} 11 \mathrm{~b}$, or secreted proteins such as IFN- $\gamma$, IL-2, or
TNF-a could be highly useful for characterizing the tumor immune landscape with a reduced wait time post-injection.

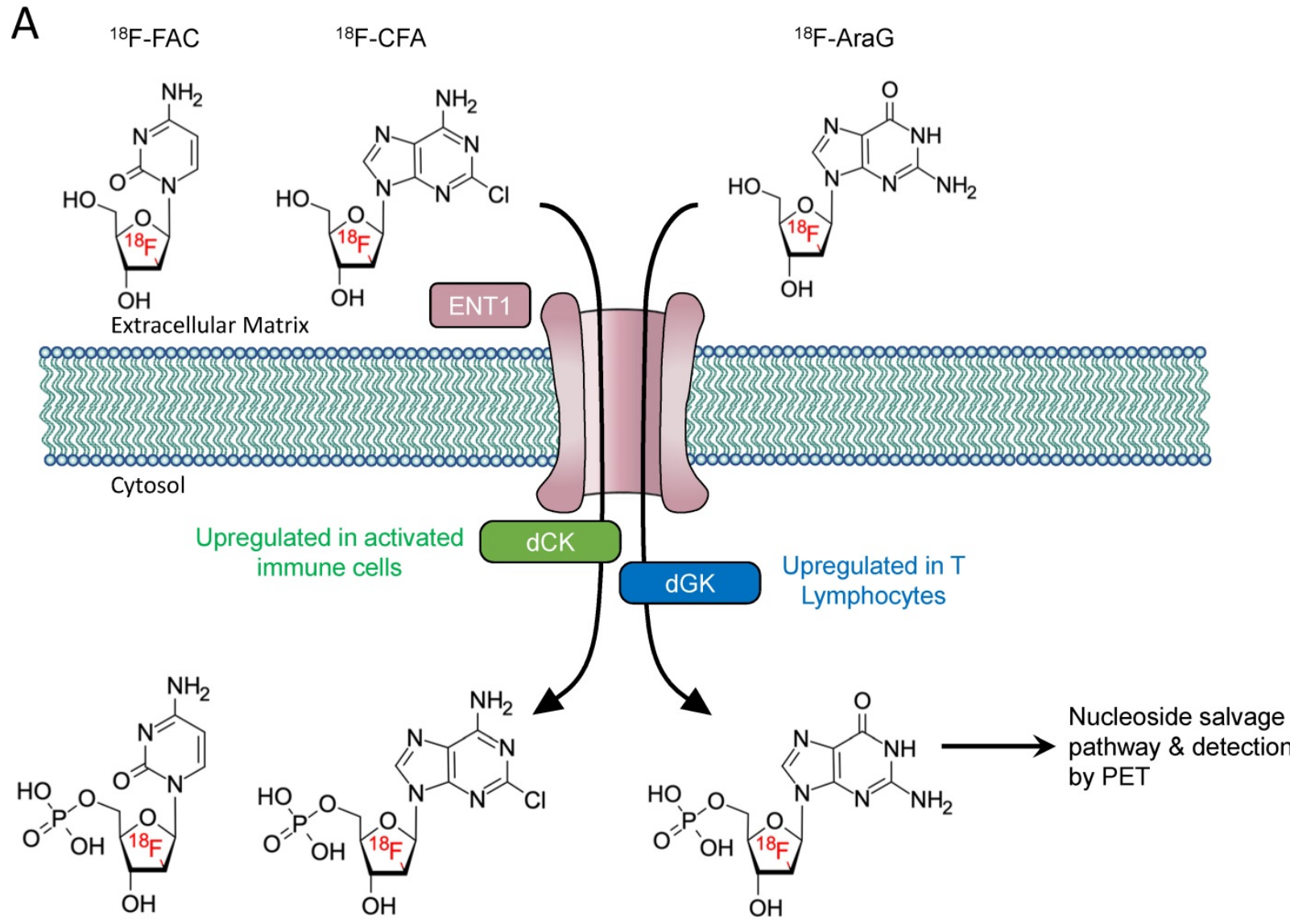

B ${ }^{18} \mathrm{~F}-\mathrm{CFA}$

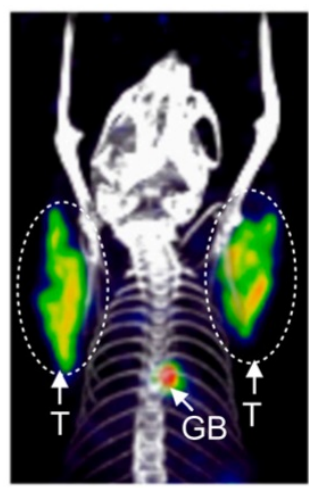

${ }^{18}$ F-FDG

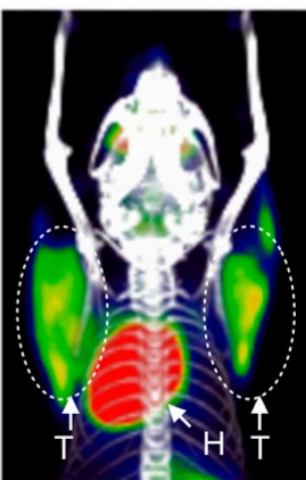

${ }^{18} \mathrm{~F}-\mathrm{CFA}$

+ dCK inhibitor

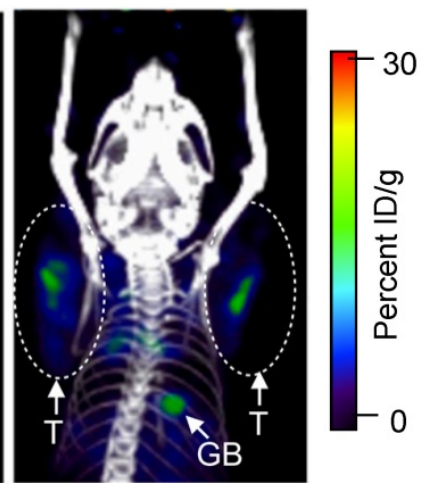

C

${ }^{18} \mathrm{~F}-\mathrm{CFA}$

Healthy Volunteer

Figure 1. Nucleoside analog-based PET imaging. (A) PET tracers 18F-AraG and 18F-CFA are transported intracellularly by equilibrative nucleoside transporter 1 (ENT1). The tracers are then phosphorylated by their targets deoxyguanosine kinase and deoxycytosine kinase, trapping them intracellularly within cells. The tracers are then further metabolized along the nucleoside salvage pathway and incorporated into newly synthesized DNA. (B) PET/CT images of mice bearing CEM tumors, a human lymphoblastic leukemia, (circled) transduced to express Cytidine Deaminase (CDA). ${ }^{18} \mathrm{~F}-\mathrm{CFA}$ was used in the left and right images, while ${ }^{18} \mathrm{~F}-\mathrm{FDG}$ was used for the center image. A small molecule inhibitor of dCK, DI-82, was used in the right image to confirm the specificity of $18 \mathrm{~F}-\mathrm{CFA}$ for dCK. Adapted from [42]. (C) ${ }^{18 F-C F A ~ P E T ~ o f ~ a ~ h e a l t h y ~ h u m a n ~ v o l u n t e e r . ~}$ Organs with high uptake are indicated with arrows. Adapted from [42]. 

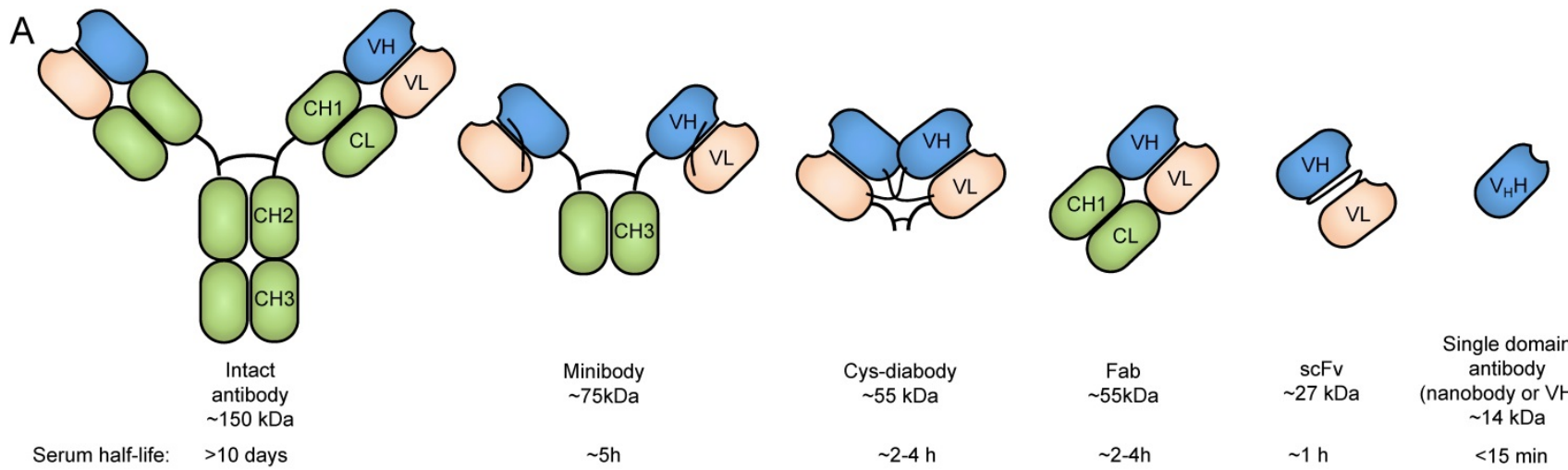

Serum half-life: $\quad>10$ days
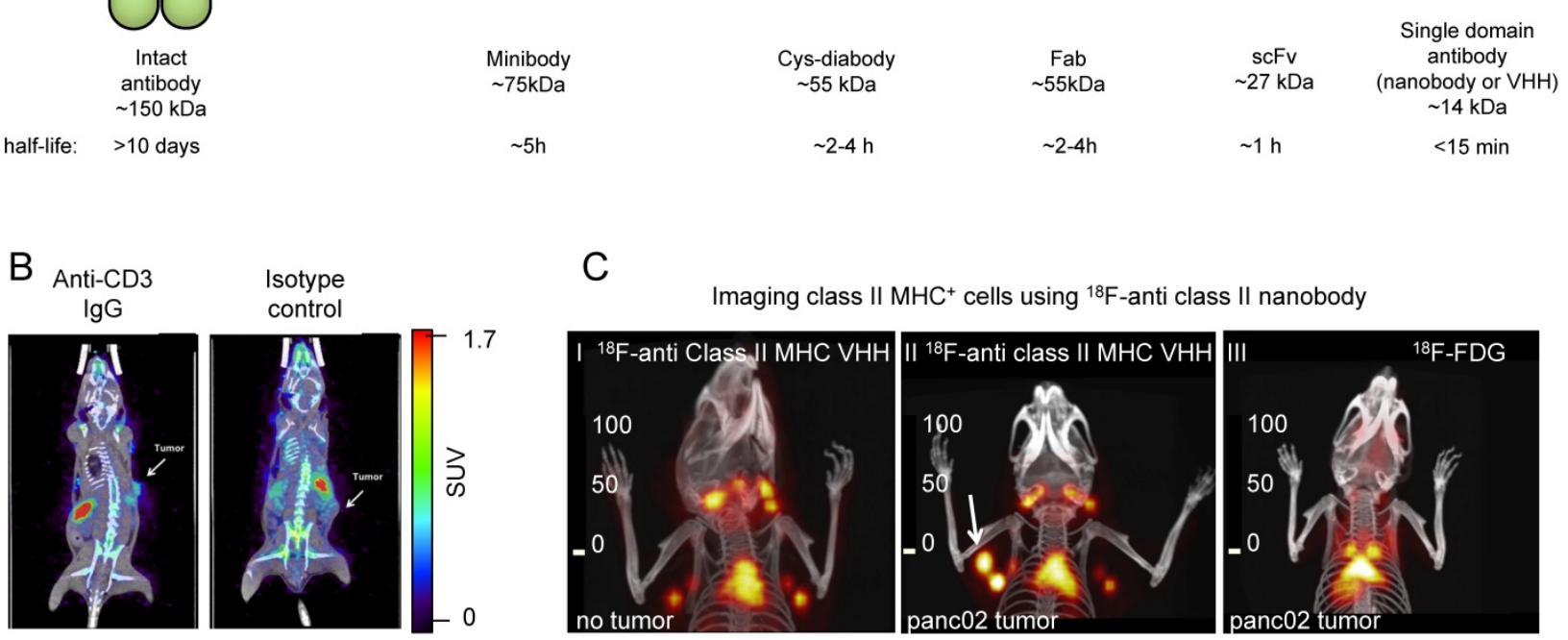

Figure 2. Antibody-based tracers for in vivo PET imaging. (A) Antibody fragments used for PET and SPECT imaging. (B) PET/CT images of mice bearing syngeneic BBN975 bladder tumors. The image on the left was acquired using an anti-CD3 IgG antibody-based tracer, while the image on the right was acquired using an isotype control lgG antibody. Images were acquired $72 \mathrm{~h}$ post injection of the tracer. Adapted from [73]. (C) C-I: ${ }^{8}$ F-labeled anti-mouse class II MHC nanobody detects lymphoid organs (thymus and lymph nodes). C-II: The $18 \mathrm{~F}$-labeled anti-mouse class II MHC nanobody detects pancreatic panc02 tumor by virtue of detecting tumor-infiltrating class II MHC+ cells (white arrow shows the tumor). C-III: 18 F-FDG fails to detect the same tumor. PET/CT images were acquired $2 \mathrm{~h}$ post-injection of the radiolabeled VHH or $18 \mathrm{~F}-\mathrm{FDG}$. Data adapted from reference [64].

\section{Radiolabeled antibodies and antibody fragments for imaging immune responses}

Due to the availability of antibodies against cell surface markers, and robust protein labeling techniques, imaging using radiolabeled antibodies has become a popular method for in vivo imaging of specific cell types. While intact antibodies have been used for imaging, their large size $(\sim 150 \mathrm{kDa})$ results in less than ideal imaging characteristics such as slow clearance from circulation ( $t_{1 / 2}$ of days to weeks), and relatively low tissue penetration. As a result, smaller antibody fragments such as minibodies, cysdiabodies, single chain Fvs (scFvs), and nanobodies have been developed and used for in vivo imaging (Figure 2A). The smaller size of these antibody fragments provides superior imaging characteristics, such as rapid clearance from circulation, higher tissue penetration, and higher signal-to-background ratios. Furthermore, these antibody fragments lack an Fc region, are not subject to recycling by the neonatal $\mathrm{FC}_{\mathrm{C}}$ receptor $(\mathrm{FcRn})$, and, therefore, have a short half-life in circulation.

While antibodies and antibody fragments vary widely in their serum half-life, pretargeting radiolabeling methods have allowed for decoupling of the tracer distribution time and the radioisotope half-life necessary for imaging [54,55]. In pretargeting, targeting antibodies or antibody fragments are labelled with a biorthogonal reactive group and injected into the subject. Then, at the desired time, the chelated radioisotope bearing a complementary reactive group is injected and allowed to react with the pretargeted vector. The subject is then ready for PET imaging. These methods are useful in cases where the targeting vector and radioisotope have incompatible half-lives (i.e. full length antibody serum $\mathrm{t}_{1 / 2}$ of days to weeks; ${ }^{18} \mathrm{~F}_{1 / 2}$ of 109 minutes).

ImmunoPET has been used for in vivo imaging of cancer-specific markers, such as HER2 and EGFR $[20,56]$. Detection of these markers has valuable applications in early detection of cancer, noninvasive tumor characterization, and guiding treatment decisions. Success in imaging cancer-specific markers in preclinical models has led to several clinical studies. In one such clinical trial, ${ }^{89} \mathrm{Zr}$-labeled trastuzumab was used to gauge the response of HER2 ${ }^{+}$breast cancer patients to an anti-HER2 therapy [57]. Combined imaging before and after treatment had a $100 \%$ success rate in predicting patient response as assessed by time to treatment failure [57]. While these results point toward promising applications of 
immuno-PET for tumor characterization and guiding targeted treatment, imaging of cancer-specific markers is usually unable to provide information assessing the tumor immune landscape or the immune response to immunotherapeutics.

Targeted imaging of immune cells can be used to assess the tumor immune landscape. Myeloid cells play key roles in shaping the immune status of the TME $[58,59]$. Therefore, imaging their presence and activation status can help better assess the response to immunotherapy. Tumor-associated macrophages can significantly influence the TME immune landscape, for example by secreting different cytokines. M1-like macrophages secrete inflammatory cytokines such as CCL5, CXCL9 and CXCL10, which can recruit and activate $\mathrm{T}$ cells, whereas M2-like macrophages secrete cytokines that repel $\mathrm{T}$ cells. Thus, imaging the presence and phenotypic status of macrophages in the TME can provide valuable information for the assessment of immunotherapy response. A ${ }^{99 \mathrm{mTc}-}$ labeled nanobody targeting the Macrophage Mannose Receptor (MMR, or CD206), which is highly expressed by the immunosuppressive M2-like macrophages, has been utilized for SPECT imaging in preclinical models of lung and mammary tumors. $\mathrm{MMR}^{+}$macrophages were detected in hypoxic regions of the tumor with clarity in both cancer models, as early as 3 hours postinjection [60]. Later PET imaging with a human/ mouse MMR cross-reactive ${ }^{18} \mathrm{~F}$-labeled nanobody in a mouse model of lung cancer validated $\mathrm{MMR}^{+}$ macrophage imaging [61]. This anti-MMR nanobody has moved into clinical trial, where it will be used to detect tumor associated macrophages in patients (NCT04168528) [62]. These studies indicate that imaging of $\mathrm{MMR}^{+}$macrophages in the TME is feasible, and future studies will investigate whether it has predictive value for cancer immunotherapy.

$\mathrm{CD} 11 \mathrm{~b}$ is a myeloid cell marker that has served as a target for PET imaging of myeloid cells. An antiCD11b ${ }^{99 m}$ Tc-labeled intact antibody has been used for SPECT imaging of myeloid cells in a mouse colon cancer model. Animals showed high tumor uptake of the tracer indicating the presence of myeloid cells 6 hours post-injection [63]. An anti-CD11b nanobody was also used to image tumor infiltration of myeloid cells in a melanoma model and could detect the tumor with clarity. Importantly, penetration of $\mathrm{CD} 11 \mathrm{~b}^{+}$cells to the tumor core was found to be a negative predictor of tumor response to PD-1 blockade [64]. Hence, CD11b-targeted PET could be a valuable tool for assessment of the TME in the clinic.

Professional antigen presenting cells, including macrophages, B cells, and dendritic cells, are pivotal to the development of an anti-tumor immune response. These cells are unique in their expression of
MHC class II which is used to present tumor antigens to $\mathrm{CD}^{+} \mathrm{T}$ cells. A nanobody against mouse MHC class II was developed and used for in vivo detection of tumor infiltrating class II positive cells in both syngeneic and xenogeneic preclinical models. This ${ }^{18} \mathrm{~F}-$-radiolabaled nanobody could detect tumors with clarity, by virtue of detecting infiltrating class II positive cells as early as 2 hours post-injection [64,65]. An anti-human class II nanobody was also developed and used to image class II positive cells in a humanized mouse model of Graft versus Host Disease (GvHD). Mice that developed GvHD showed high uptake of the anti-class II tracer in the liver, corresponding to an increase of $\mathrm{MHC} \mathrm{II}^{+}$immune cells [66]. Furthermore, nanobody-based tracers specific for dendritic cells have been developed [67]. While the importance of professional antigen presenting cells in the TME has been acknowledged, further studies are needed to determine whether in vivo imaging of this subset holds prognostic value.

Natural killer cells can mediate an anti-tumor response against cancer cells that down regulate MHC class I expression and are thus a valuable target for PET imaging. NKp30, a natural cytotoxicity receptor that is upregulated on activated natural killer cells has been used as a target for PET imaging [68]. NSG mice, lacking autologous NK cells were injected with NK92MI cells, an immortalized NK cell line. Mice were later injected with a ${ }^{64} \mathrm{Cu}$-labelled antiNKp30 and imaged $48 \mathrm{~h}$ later. Mice injected with NK92MI cells showed high uptake in the spleen, indicating an NK cell-specific signal [68]. Other studies have assessed NK cell and NK CAR cell tumor infiltration by ex vivo labelling $[69,70]$. Further studies are needed to explore to what extent immunoPET can be used to assess NK cell tumor infiltration.

Of particular interest is the imaging of $\mathrm{T}$ cell infiltration of tumors as a potential prognostic and predictive factor. Cytotoxic $\mathrm{CD}^{+} \mathrm{T}$ cells directly mediate much of the anti-tumor immune response induced by checkpoint blockade and, thus, are a potential target for tumor characterization and monitoring the progress of immunotherapeutics [71]. Likewise, $\mathrm{CD}^{+} \mathrm{T}$ cells play an important role in shaping the TME, and monitoring their tumor penetration holds prognostic value [72]. Several strategies have been developed to image $\mathrm{T}$ cells in both preclinical and clinical settings. This includes using antibody and antibody fragments targeting CD3, CD4 and CD8, specific markers of T cells, helper $\mathrm{T}$ cells and cytotoxic $\mathrm{T}$ cells, respectively. A ${ }^{89} \mathrm{Zr}$-radiolabeled anti-CD3 antibody was found to be able to detect tumor infiltrating lymphocytes in a syngeneic murine model, 72 hours post injection (Figure 2B) [73]. In vivo imaging using a ${ }^{89} \mathrm{Zr}$-radio- 
labeled anti-CD4 cys-diabody resulted in high uptake in lymphoid organs, with favorable signal/ background ratios, $20 \mathrm{~h}$ post-injection [74]. Minibodies specific for mouse CD8 have been developed for PET imaging of $\mathrm{CD}^{+} \mathrm{T}$ cells. The ${ }^{89} \mathrm{Zr}$-radiolabeled minibodies resulted in high uptake in the lymphoid organs in mice, when imaged 4 hours post-injection [24]. These studies demonstrate that in vivo imaging of $\mathrm{T}$ cells is feasible.

Other studies were able to correlate $\mathrm{T}$ cell infiltration into tumors with treatment outcomes. A ${ }^{89} \mathrm{Zr}$-labeled anti-CD3 antibody was used to assess the immune-mediated response to CTLA- 4 blockade, 3 days post-injection of the tracer in a preclinical colorectal cancer model [75]. After anti-CTLA-4 treatment, it was found that responders had higher $\mathrm{T}$ cell infiltration compared to nonresponders. The authors concluded that the anti-CD3 imaging could stratify responding tumors based on their $\mathrm{T}$ cell infiltration. A cys-diabody against CD8 was developed for the detection of tumor infiltrating CD8 ${ }^{+}$ lymphocytes in vivo [76]. In a murine model of colorectal cancer, mice were treated with an anti-PD1 antibody and imaged 48 hours later; images were acquired 22 hours post injection of the tracer. It was found that greater infiltration of $\mathrm{CD}^{+} \mathrm{T}$ cells into tumors was predictive of response to anti-PD1 therapy [76]. A nanobody against CD8 was developed and used to detect $\mathrm{CD}^{+} \mathrm{T}$ cells in vivo. Addition of a $20 \mathrm{kDa}$ polyethylene glycol (PEG) moiety to the nanobody significantly enhanced signal-tobackground ratio and reduced uptake in the kidneys, potentially owing to its increased circulatory half-life and hydrophilicity [23]. In a B16 melanoma model, mice were treated with anti-CTLA- 4 antibody and vaccinated with irradiated B16 tumor cells engineered to secrete granulocyte-macrophage colonystimulating factor (the vaccine is usually referred to as "GVAX") [77]. The response was monitored longitudinally by CD8 PET imaging once a week for 4 weeks. It was found that homogeneous distribution of $\mathrm{CD}^{+} \mathrm{T}$ cells in tumors was predictive of response to CTLA-4 blockade (Figure 2C) [23]. In later work, the ${ }^{89} \mathrm{Zr}$-labeled PEGylated anti-CD8 nanobody was used to image $\mathrm{T}$ cell infiltration in a PD-1 responsive colorectal cancer model [78]. Responding mice showed a significant increase in $\mathrm{T}$ cells and their penetration into the tumors, whereas nonresponding mice showed $\mathrm{CD} 8^{+} \mathrm{T}$ cells remaining mostly around the tumor periphery [78]. Imaging of $\mathrm{CD}^{+}$cells has recently begun translation to the clinic. In a recent first-in-human study, a ${ }^{89} \mathrm{Zr}$-labeled anti-CD8 minibody was used to detect $\mathrm{CD} 8{ }^{+} \mathrm{T}$ cell tumor infiltrates in patients with hepatocellular carcinoma, melanoma, and lung cancer ( ${ }^{89} \mathrm{Zr}$-labeled-IAB22M2C) [79]. The tracer showed high uptake in tumors, as well as the liver, kidneys and spleen. Images were acquired $2-4 \mathrm{~h}$, $24 \pm 4 \mathrm{~h}, 48 \pm 4 \mathrm{~h}$, and 92-148 h post injection. These studies show that infiltration of $\mathrm{T}$ cells into tumors is predictive of response to immunotherapy and can be assessed by immunoPET. This ${ }^{89} \mathrm{Zr}$-labeledIAB22M2C tracer has now moved into a phase $2 \mathrm{~A}$ open label, multi-dose trial in patients with metastatic solid tumors prior to and after standard immunotherapy (NCT03802123).

$\mathrm{T}$ cells are likely the major contributors to the anti-tumor immune response of checkpoint blockade. However, not all $\mathrm{T}$ cells can kill tumor cells or contribute in reshaping the immune landscape of the TME to a more anti-tumor status. Activated T cells, however, are likely the major cells that contribute to the anti-tumor response of checkpoint blockade. Therefore, the ability to detect their infiltration into tumors holds great prognostic value. While detection of TILs through anti-CD3 or anti-CD8 antibodies has been used to predict the response to immunotherapy in murine models, detected T cells may be exhausted or anergic and not capable of actively mounting an anti-tumor response. An important attribute of activated $T$ cells is their increased surface expression of costimulatory molecules such as ICOS, 4-1BB, and OX40 [80-82]. As such, one strategy to image activated immune cells is to use radiolabeled antibodies against these molecules. A recent study used a ${ }^{89} \mathrm{Zr}$-labeled intact antibody against ICOS to detect activated $\mathrm{CD}^{+}{ }^{+}$and $\mathrm{CD} 8^{+} \mathrm{T}$ cells in vivo [83]. In a lung cancer model, tracer uptake in the tumor and tumor draining lymph nodes predicted the tumor growth rate response to a stimulator of interferon genes (STING) agonist treatment, 2 days post-injection. In similar work, a radiolabeled anti-OX40 intact antibody was used to detect activated $\mathrm{T}$ cells in vivo [84]. In mice bearing A20 B cell leukemia tumors, tracer uptake in the tumors and tumor draining lymph nodes 4, 16, and 24 hours after tracer administration, successfully predicted response to $\mathrm{CpG}$ vaccination. These results show that imaging of activated $\mathrm{CD}^{+} \mathrm{T}$ cells is a valuable tool for assessing the immune response to cancer immunotherapy.

The presence of tumor-specific T cells in the TME has been shown to be essential for mounting an effective anti-tumor immune response $[85,86]$. Imaging antigen-specific $\mathrm{T}$ cells is thus of great importance. A recent study used a peptide-loaded ${ }^{64} \mathrm{Cu}$ labeled MHC construct dimerized via an Fc fragment to image, in vivo, HPV and influenzaspecific $\mathrm{CD}^{+} \mathrm{T}$ cells in the context of HPV-tumorbearing and influenza-infected mice, respectively [87].

Taken together, a large body of preclinical data suggests that imaging immune cells by immuno-PET 
can be used to assess, prognosticate and even predict the response to cancer immunotherapy, some of which have already moved into clinical trials. In the future, we can anticipate the development of more preclinical approaches and translation of more of these efforts into clinical settings, where they will help guide clinical decision-making.

\section{Imaging cytokines}

While defects in oncogenes and tumor suppressor genes underlie a genetic component of cancer, the microenvironment that tumors inhabit has a great influence on tumor growth and the immune-mediated response to cancer. Cytokines within the TME can contribute to an inflammatory or anti-inflammatory TME (Figure 3). Pro-inflammatory cytokines can contribute to an anti-tumor response by enhancing cytotoxicity, increasing tumor antigen presentation, recruiting $\mathrm{T}$ cells and inducing cancer apoptosis [88], while anti-inflammatory cytokines can induce an immunosuppressive tumor landscape [89]. Therefore, detection of cytokines in the TME can provide information about the immune landscape of the tumor and allow for assessment or even prediction of the response to immunotherapy. Of note, circulating cytokines can also bind to the PET tracers, which may impair the detection of cytokines in the TME.

Several preclinical studies have been performed to noninvasively image cytokines (Table 1A - Table 1E). A ${ }^{89} \mathrm{Zr}$-labeled anti-IFN- $\gamma$ antibody has been used to detect IFN- $\gamma$ in the TME of a mammary cancer model [28]. Mice were inoculated with HER2+ tumors and treated with a HER2-based DNA vaccine, encoding the extracellular and transmembrane regions of HER2 as well as GM-CSF, which upon secretion would help to recruit antigen-presenting cells and thus enhance tumor-specific T cell priming. Vaccinated mice showed higher uptake of the tracer in tumors, indicating increased antitumor immunity. The tracer uptake was negatively correlated with the tumor growth rate [28]. In another study, the TNF- $\alpha$ inhibitor etanercept was radiolabeled with ${ }^{64} \mathrm{Cu}$ and used for PET imaging of TNF-a in a model of acute and chronic inflammation [90]. Mice were injected in the right ear with 12-O-tetradecanoyl-phorbol-13acetate (TPA) to induce inflammation. After a single injection of TPA, tracer uptake significantly increased in the right ear, indicating increased inflammation.

Table 1A. ImmunoPET Tracers

\begin{tabular}{|c|c|c|c|c|c|c|c|}
\hline Target & Agent & Class & Reactivity & Stage & $\begin{array}{l}\text { Concluded } \\
\text { Clinical Trials }\end{array}$ & Active clinical trials & References \\
\hline Macrophage & 99mTc-d a-MMR Nb cl1 & Nanobody & Mouse & Preclinical & & & [60] \\
\hline \multirow{2}{*}{$\begin{array}{l}\text { Mannose Receptor } \\
\text { (MMR) }\end{array}$} & ${ }^{18} \mathrm{~F}-\mathrm{FB}$-anti-MMR 3.49 & Nanobody & Human, Mouse & Preclinical & & & [61] \\
\hline & ${ }^{68} \mathrm{Ga}-\mathrm{NOTA}$-Anti-MMR-VHH2 & Nanobody & Human & Clinical & & NCT04168528 & [62] \\
\hline \multirow[t]{2}{*}{ MHC II } & ${ }^{18} \mathrm{~F}-\mathrm{FDG}-\mathrm{VHH7}$ & Nanobody & Mouse & Preclinical & & & [64] \\
\hline & ${ }^{64} \mathrm{Cu}-\mathrm{VHH} 4$ & Nanobody & Human & Preclinical & & & {$[66]$} \\
\hline CD3 & ${ }^{89} \mathrm{Zr}-\mathrm{DFO}-\mathrm{CD} 3$ (clone 17A2) & Intact antibody & Mouse & Preclinical & & & {$[73,75]$} \\
\hline $\mathrm{CD} 4$ & ${ }^{89} \mathrm{Zr}-\mathrm{GK} 1.5 \mathrm{cDb}$ & Cys-diabody & Mouse & Preclinical & & & [74] \\
\hline ICOS & ${ }^{89} \mathrm{Zr}-\mathrm{DFO}-\mathrm{ICOS} \mathrm{mAb}$ & Intact antibody & Mouse & Preclinical & & & [83] \\
\hline OX40 & ${ }^{64} \mathrm{Cu}-\mathrm{DOTA}-\mathrm{AbOX} 40$ & Intact antibody & Mouse & Preclinical & & & [84] \\
\hline \multirow[t]{2}{*}{ CD11b } & ${ }^{89} \mathrm{Zr}-\mathrm{PEG}-\mathrm{DC} 13$ & Nanobody & Mouse & Preclinical & & & [78] \\
\hline & 99mTc-MAG3-anti-CD11b (clone EP1345Y) & Intact Antibody & Mouse & Preclinical & & & [63] \\
\hline \multirow[t]{3}{*}{ CD8 } & ${ }^{89} \mathrm{Zr}-\mathrm{Df}-\mathrm{IAB} 22 \mathrm{M} 2 \mathrm{C}$ & Minibody & Human & Clinical & NCT03107663 & NCT03802123 & [79] \\
\hline & YTS169-64Cu-NOTA & Minibody & Mouse & Preclinical & & & [24] \\
\hline & YTS2.43-64 Cu-NOTA & Minibody & Mouse (Lyt 2.2 allele) & Preclinical & & & [24] \\
\hline Mouse Dendritic & 99m Tc-Nb-DC2.1 & Nanobody & Mouse & Preclinical & & & {$[67]$} \\
\hline Cells & ${ }^{99 \mathrm{~m}} \mathrm{Tc}-\mathrm{Nb}-\mathrm{DC} 1.8$ & Nanobody & Mouse & Preclinical & & & \\
\hline
\end{tabular}

Table 1B. Cytokine tracers table

\begin{tabular}{|c|c|c|c|c|c|c|c|}
\hline Target & Agent & Class & Reactivity & Stage & $\begin{array}{l}\text { Concluded } \\
\text { Clinical Trials }\end{array}$ & Active clinical trials & References \\
\hline IFN- $\gamma$ & ${ }^{89} \mathrm{Zr}-\mathrm{DFO}-\mathrm{AN}-18$ & Intact antibody & Mouse & Preclinical & & & {$[28]$} \\
\hline TNF- $a$ & ${ }^{64} \mathrm{Cu}$-DOTA-etanercept & $\begin{array}{l}\text { Anti-TNF- } \alpha \text { drug } \\
\text { (Etanercept) }\end{array}$ & Human, Mouse & Preclinical & & & [90] \\
\hline Granzyme B & ${ }^{68} \mathrm{Ga}-N O T A-G Z P$ & Peptide & Mouse & Preclinical & & & {$[53]$} \\
\hline TGF- $\beta$ & ${ }^{89} \mathrm{Zr}$-fresolimumab & Intact antibody & Human & Clinical & NTC01472731 & & [91] \\
\hline \multirow[t]{3}{*}{ IL-2 receptor } & ${ }^{18}$ F-FB-IL-2 & Labeled cytokine (IL-2) & Human, Mouse & Clinical & $\begin{array}{l}\text { NCT02922283 } \\
\text { (Terminated) }\end{array}$ & $\begin{array}{l}\text { NCT03304223, NCT04163094, } \\
\text { NCT02478099 }\end{array}$ & [92] \\
\hline & ${ }^{68} \mathrm{Ga}-\mathrm{Ga}-\mathrm{NODAGA}-\mathrm{IL} 2$ & Labeled cytokine (IL-2) & Human, Mouse & Preclinical & & & [93] \\
\hline & ${ }^{18} \mathrm{~F}-\mathrm{AlF}-\mathrm{RESCA}-\mathrm{IL} 2$ & Labeled cytokine (IL-2) & Human, Mouse & Preclinical & & & \\
\hline
\end{tabular}


Table 1C. Small Molecule Tracers

\begin{tabular}{lllll}
\hline Agent & Target & Stage & Concluded Clinical Trials & Active clinical trials \\
\hline${ }^{18 \text { F-FAC }}$ & Deoxycytidine kinase $(\mathrm{dCK})$ & Clinical & NCT01180907, NCT01180868 & References \\
${ }^{18 \text { F-CFA }}$ & dCK & Clinical & & NCT03409419 \\
${ }^{18 \text { F-F-AraG }}$ & Deoxyguanosine kinase (dGK) & Clinical & NCT03007719 (Terminated), & NCT04052412, NCT03142204, NCT04186988, \\
& & & NCT02323893 & NCT03129061, NCT03684655, NCT03367962 \\
1-L-18F-FETrp & IDO & Preclinical & & \\
${ }^{68}$ Ga-NOTA-GZP & Granzyme B (Mouse) & Preclinical & & [52]
\end{tabular}

Table 1D. Imaging Engineered T cells

\begin{tabular}{|c|c|c|c|c|c|c|c|}
\hline \multirow{2}{*}{ Ex vivo } & \multirow{2}{*}{$\begin{array}{l}\text { Agent } \\
{ }^{89} \mathrm{Zr} \text {-oxine }\end{array}$} & \multicolumn{4}{|l|}{ Method } & \multirow{2}{*}{$\begin{array}{l}\text { Stage } \\
\text { Preclinical }\end{array}$} & References \\
\hline & & \multicolumn{4}{|l|}{ Passive diffusion } & & {$[148]$} \\
\hline & ${ }^{89} \mathrm{Zr}-\mathrm{DBN}$ & \multicolumn{4}{|c|}{ Cell surface bound } & Preclinical & {$[149,150]$} \\
\hline & Reporter gene & Species & Type & Properties & Agent & Stage & \\
\hline \multirow[t]{7}{*}{ In vivo } & $\begin{array}{l}\text { Herpes Simplex Virus - Thymidine } \\
\text { Kinase (HSV-TK) }\end{array}$ & $\begin{array}{l}\text { Herpes Simplex } \\
\text { Virus } 1\end{array}$ & Enzyme & $\begin{array}{l}\text { Kinase causing intracellular } \\
\text { containment of PET tracer }\end{array}$ & ${ }^{18} \mathrm{~F}-\mathrm{FHBG}$ & Clinical & {$[27,154]$} \\
\hline & Glutamate carboxypeptidase 2 (PSMA) & Human & Cell surface enzyme & Enzyme that produces glutamate & ${ }^{18 F-D C F P y L ~}$ & Preclinical & [168] \\
\hline & Sodium Iodine Symporter (NIS) & Human & Transporter & Symports sodium and iodine & ${ }^{99} \mathrm{mTCO}_{4}^{-}$ & Preclinical & [158] \\
\hline & Norepinephrine Transporter (NET) & Human & Cell surface receptor & G-protein coupled receptor & 123I-MIBG, ${ }^{124}$ I-MIBG & Preclinical & [159] \\
\hline & Somatostatin Receptor 2 (SSTR2) & Human & Cell surface receptor & G-protein coupled receptor & ${ }^{68} \mathrm{Ga}$-DOTATOC & Preclinical & [160] \\
\hline & 2D12.5/G54C & Murine & Cell surface receptor & Membrane-bound antibody & ${ }^{86} \mathrm{Y}-\mathrm{AABD}$ & Preclinical & {$[178]$} \\
\hline & Dihydrofolate reductase enzyme (DHFR) & Escherichia coli & Enzyme & $\begin{array}{l}\text { Enzyme that produces } \\
\text { tetrahydrofolate }\end{array}$ & ${ }^{18} \mathrm{~F}-\mathrm{TMP}$ & Preclinical & [179] \\
\hline
\end{tabular}

Table 1E. Imaging Checkpoint molecules

\begin{tabular}{|c|c|c|c|c|c|c|c|}
\hline Target & Agent & Class & Reactivity & Stage & Concluded Clinical Trials & Active clinical trials & References \\
\hline \multirow[t]{24}{*}{ PD-L1 } & ${ }^{18} \mathrm{~F}-\mathrm{B} 3,{ }^{64} \mathrm{Cu}-\mathrm{B} 3$ & Nanobody & Murine & Preclinical & & & [105] \\
\hline & 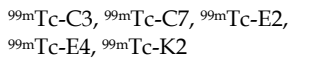 & Nanobody & Murine & Preclinical & & & {$[106,107]$} \\
\hline & ${ }^{64} \mathrm{Cu}-\mathrm{NOTA}-10 \mathrm{~F} .9 \mathrm{G} 2$ & Antibody IgG2b & Murine & Preclinical & & & {$[100]$} \\
\hline & ${ }^{89} \mathrm{Zr}-\mathrm{DFO}-10 \mathrm{~F} .9 \mathrm{G} 2$ & Antibody IgG2b & Murine & Preclinical & & & [103] \\
\hline & ${ }^{111}$ In-DTPA-anti-PDL1 & Antibody & Murine & Preclinical & & & {$[180,181]$} \\
\hline & ${ }^{68} \mathrm{Ga}-\mathrm{WL} 12$ & Peptide & Human & Preclinical & & & [182] \\
\hline & 18F-FPy-WL12 & Peptide & Human & Preclinical & & & [183] \\
\hline & ${ }^{18}$ F-NOTA-Z & Affibody & Human & Preclinical & & & [108] \\
\hline & ${ }^{64} \mathrm{Cu}-\mathrm{DOTA}-\mathrm{FN} 3 \mathrm{hPD}-\mathrm{L} 1$ & Adnectin & Human & Preclinical & & & [118] \\
\hline & 68Ga-NOTA-Nb109 & Nanobody & Human & Preclinical & & & [184] \\
\hline & ${ }^{64} \mathrm{Cu}-\mathrm{DOTA}-\mathrm{HAC}-\mathrm{PD} 1$ & $\begin{array}{l}\text { High Affinity PD-1 } \\
\text { ectodomain }\end{array}$ & Human & Preclinical & & & {$[185,186]$} \\
\hline & ${ }^{64} \mathrm{Cu}$-NOTA-avelumab Fab & $\mathrm{Fab}$ & Human & Preclinical & & & [187] \\
\hline & ${ }^{111}$ In-labeled atezolizumab & Antibody IgG1 & Human & Preclinical & & & [188] \\
\hline & ${ }^{64} \mathrm{Cu}$-DOTA-atezolizumab & Antibody IgG1 & Human & Preclinical & & & {$[111,188]$} \\
\hline & ${ }^{111} \mathrm{In}-\mathrm{PD}-\mathrm{L} 1.3 .1$ & Antibody IgG1 & Human & Preclinical & & & [189] \\
\hline & ${ }^{89} \mathrm{Zr}-\mathrm{DFO}-\mathrm{C} 4$ & Antibody IgG1 & Human & Preclinical & & & [190] \\
\hline & ${ }^{64} \mathrm{Cu}-\mathrm{WL} 12$ & Peptide & Human & Clinical & & NCT04304066 & {$[109,174]$} \\
\hline & 99mTc-NM-01 & Nanobody & Human & Clinical & NCT02978196 & & [173] \\
\hline & ${ }^{89} \mathrm{Zr}$-envafolimab & Nanobody Fc fusion & Human & Clinical & & NCT03638804 & {$[191,192]$} \\
\hline & ${ }^{18} \mathrm{~F}-\mathrm{BMS}-986192$ & Adnectin & Human & Clinical & 2015-004760-11 & $\begin{array}{l}\text { NCT03520634, NCT03843515, NCT03564197, } \\
\text { NCT03843515, 2018-002643-28, }\end{array}$ & {$[120,193]$} \\
\hline & ${ }^{89} \mathrm{Zr}$-durvalumab & Antibody IgG1 & Human & Clinical & & 2015-005765-23, NCT03829007, NCT03853187 & \\
\hline & ${ }^{89} \mathrm{Zr}$-labeled avelumab & Antibody IgG1 & Human & Clinical & & NCT03514719 & {$[113]$} \\
\hline & ${ }^{89} \mathrm{Zr}$-labeled atezolizumab & Antibody IgG1 & Human & Clinical & $\begin{array}{l}\text { NCT02453984, } \\
\text { NCT02478099 }\end{array}$ & $\begin{array}{l}\text { NCT03850028, NCT04006522, NCT04222426, } \\
\text { NCT02478099, 2019-001197-28, 2017-003511-20 }\end{array}$ & {$[112]$} \\
\hline & ${ }^{89} \mathrm{Zr}-\mathrm{CX}-072$ & Pro-antibody & Human & Clinical & & $2016-002490-36$ & [114] \\
\hline \multirow[t]{6}{*}{ PD-1 } & PD-1-liposome-DOX-64 Cu & Liposome & Murine & Preclinical & & & [194] \\
\hline & ${ }^{64} \mathrm{Cu}$-DOTA-J43 & Antibody IgG & Murine & Preclinical & & & [123] \\
\hline & ${ }^{64} \mathrm{Cu}-\mathrm{NOTA}-\mathrm{RMP} 1-14$ & Antibody IgG2a & Murine & Preclinical & & & {$[100]$} \\
\hline & ${ }^{64} \mathrm{Cu}$-pembrolizumab & Antibody IgG4 & Human & Preclinical & & & {$[126,195]$} \\
\hline & ${ }^{89} \mathrm{Zr}$-pembrolizumab & Antibody IgG4 & Human & Clinical & & $\begin{array}{l}\text { NCT02760225, NCT03065764, NCT03446911*, } \\
\text { 2015-004260-10, 2016-003819-36 }\end{array}$ & {$[124,126]$} \\
\hline & ${ }^{89} \mathrm{Zr}$-nivolumab & Antibody IgG4 & Human & Clinical & 2015-004760-11 & & {$[120,127]$} \\
\hline \multirow[t]{6}{*}{ CTLA-4 } & ${ }^{18} \mathrm{~F}-\mathrm{H} 11,{ }^{89} \mathrm{Zr}-\mathrm{H} 11$ & Nanobody & Murine & Preclinical & & & [196] \\
\hline & ${ }^{64} \mathrm{Cu}$-DOTA-anti-CTLA-4 & Antibody IgG1 & Murine & Preclinical & & & [134] \\
\hline & $\begin{array}{l}{ }^{64} \mathrm{Cu}-\mathrm{NOTA} \text {-ipilimumab-F(ab } \\
{ }^{2} 2\end{array}$ & $\mathrm{~F}\left(\mathrm{ab}^{\prime}\right)_{2}$ & Human & Preclinical & & & [135] \\
\hline & ${ }^{64} \mathrm{Cu}-\mathrm{NOTA}$-ipilimumab & Antibody IgG1 & Human & Preclinical & & & [135] \\
\hline & ${ }^{64} \mathrm{Cu}$-DOTA-ipilimumab & Antibody IgG1 & Human & Preclinical & & & [197] \\
\hline & ${ }^{89} \mathrm{Zr}$-ipilimumab & Antibody IgG1 & Human & Clinical & & NCT03313323, 2012-003616-31 & \\
\hline
\end{tabular}

*PET imaging using radiotracer is considered a secondary outcome. 


\section{Anti-tumor TME}

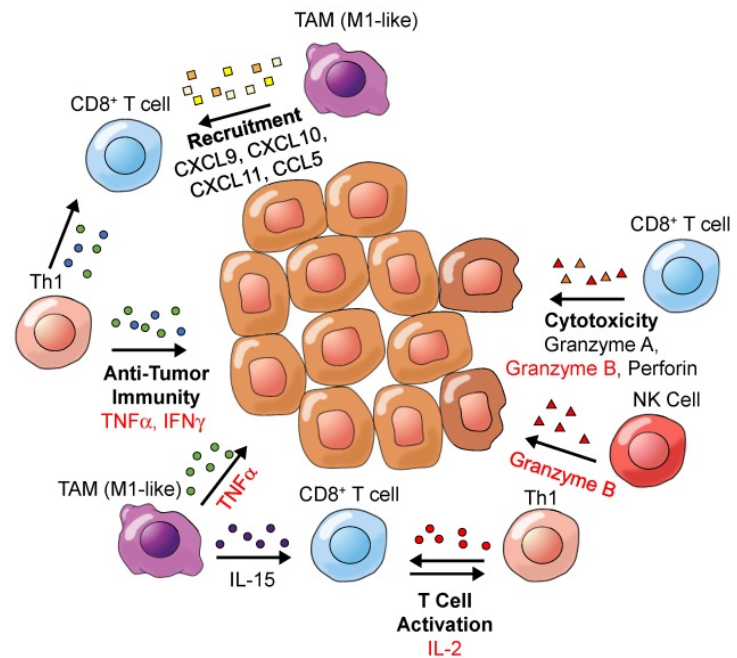

Pro-tumor TME

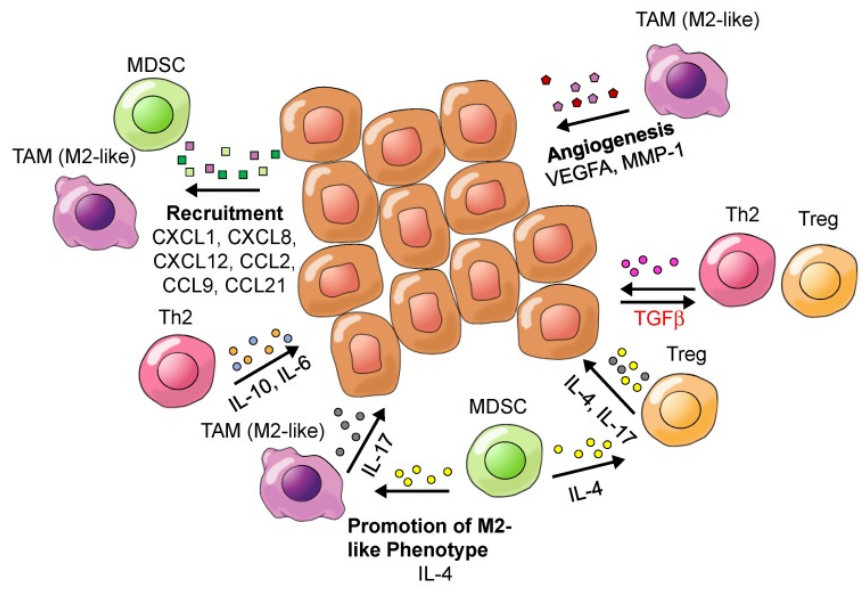

Figure 3. Cytokines and potential imaging targets of the tumor microenvironment (TME). Depicted are cytokines present in either a pro-tumor or an anti-tumor TME, which could be targeted for tumor characterization by PET. Cytokine names that have been imaged in prior studies are written in red; cytokines that have not been previously imaged are written in black. Cytokine categories are written in bold. Arrows point from cells secreting cytokines toward target cells.

PET imaging has also been used to assess the tumor penetration of cytokine-targeted antibodies in patients. In a clinical trial (NCT01472731), patients with recurrent high grade GBM were imaged with ${ }^{89} \mathrm{Zr}$-fresolimumab, a radiolabeled anti-TGF- $\beta$ monoclonal antibody [91]. The purpose of the study was to assess the tumor penetration and therapeutic efficacy of fresolimumab. ${ }^{89} \mathrm{Zr}$-fresolimumab showed high uptake in high-grade gliomas, though fresolimumab showed no clinical benefit. This study indicates that cytokine-targeted PET tracers are capable of penetrating patient tumors, and immunoPET may be able to detect cytokines in the TME of patients.

Another PET imaging strategy has involved the use of radiolabeled cytokines to detect activated $\mathrm{T}$ cells, or other immune cells, expressing their cognate receptors. Several studies have used Interleukin-2 (IL-2)-based tracers for detection of activated T cells expressing the IL-2 receptor [92,93]. More recently, $\mathrm{N}$-(4-[18$\left.{ }^{18} \mathrm{~F}\right]$ fluorobenzoyl)-IL-2 $\left.{ }^{18} \mathrm{~F}-\mathrm{FB}-\mathrm{IL}-2\right)$ has been used to detect activated T cells in the TME of a lung cancer model [92]. Tumor bearing mice were treated with either tumor-specific vaccination or X-ray irradiation. Mice whose tumors were irradiated and those that received a vaccine showed greater uptake of ${ }^{18} \mathrm{~F}-\mathrm{FB}-\mathrm{IL}-2$ in their tumors, indicating an increased presence of activated T cells. Notably, ${ }^{18} \mathrm{~F}-\mathrm{FB}-\mathrm{IL}-2 \mathrm{PET}$ imaging has advanced to clinical trials (NCT02922283, NCT03304223, NCT04163094, NCT02478099). However, the first such clinical trial was terminated, as tracer uptake did not correlate with treatment outcomes (NCT02922283).

These data demonstrate that imaging of cytokines and their receptors can be useful for gauging the anti-tumor immune status of the TME. There is a need to better understand the dynamics of different cytokines, such as CCL5, CXCL9, CXCL10, TGF- $\beta$ or IL-15, in the TME and their correlation with the treatment outcome. This, in turn, may help us to better assess or predict the response to immunotherapy, or guide clinical treatment decisions otherwise.

\section{Imaging checkpoint molecules}

Immune checkpoint molecules such as PD-1 and CTLA- 4 are inhibitory molecules that regulate activity of $\mathrm{T}$ cells (Figure $4 \mathrm{~A}$ ). Immune checkpoint blockade functions by temporarily blocking these inhibitory signals of T-cell activation. As a result, this enhances the tumor-reactive $\mathrm{T}$ cell's ability to mount an effective anti-tumor response. CTLA-4 blockade may result in depletion of regulatory $\mathrm{T}$ cells, which can further help the cytotoxic $\mathrm{T}$ cells to mount a stronger response against tumors. However, such depletion has only been observed in animal studies but not in patients treated with ipilimumab (IgG1) or tremelimumab (IgG2), the two FDA-approved antiCTLA-4 antibodies [94].

Checkpoint blockade treatments have elicited favorable clinical responses in patients with melanoma, lung, head and neck, urothelial cancer, and Hodgkin lymphoma, among others [95]. Being able to noninvasively assess through PET imaging, expression and location of these immune checkpoint molecules can provide a pathway to better clinical prognostic and predictive tools [96]. 

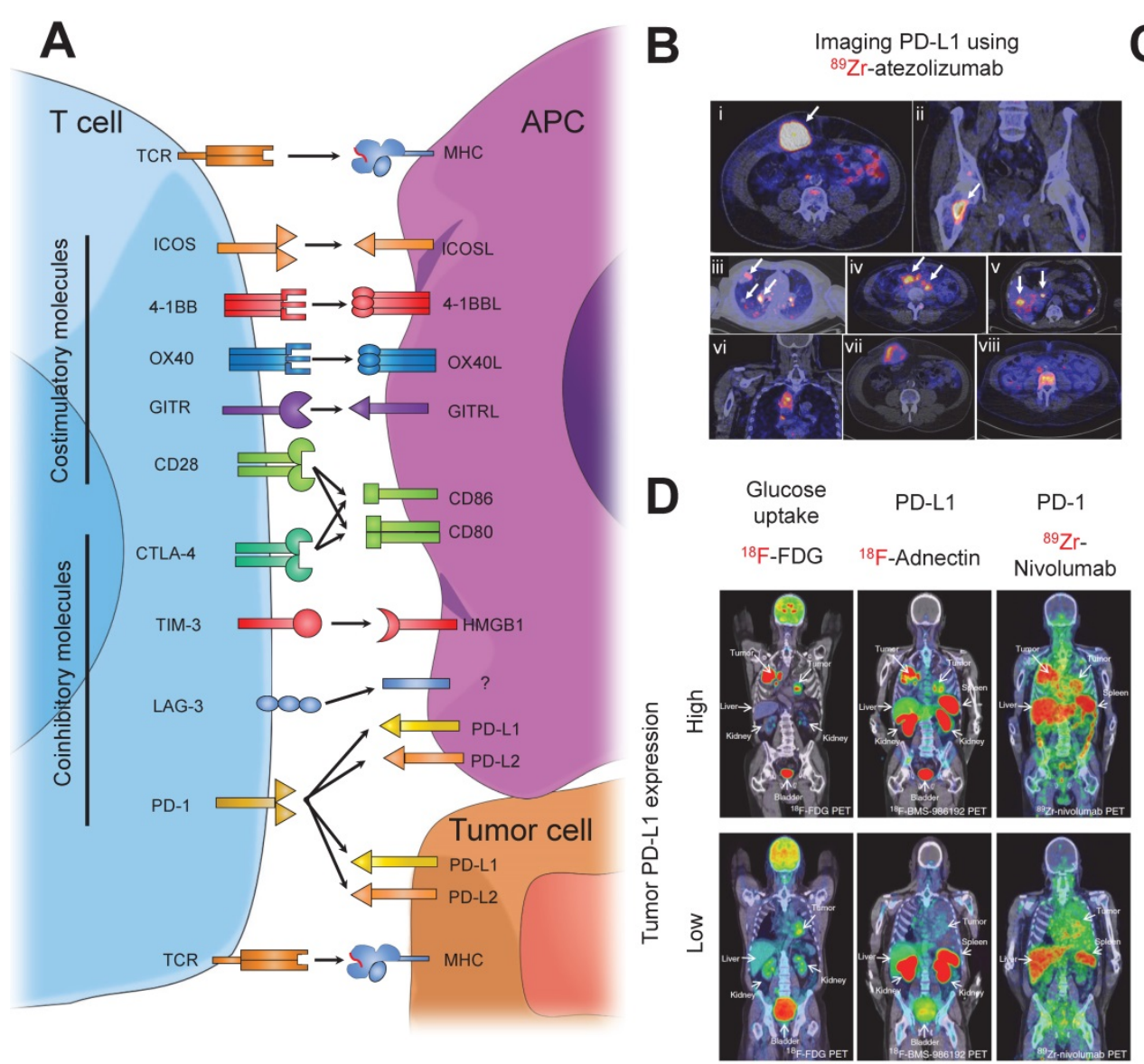

C
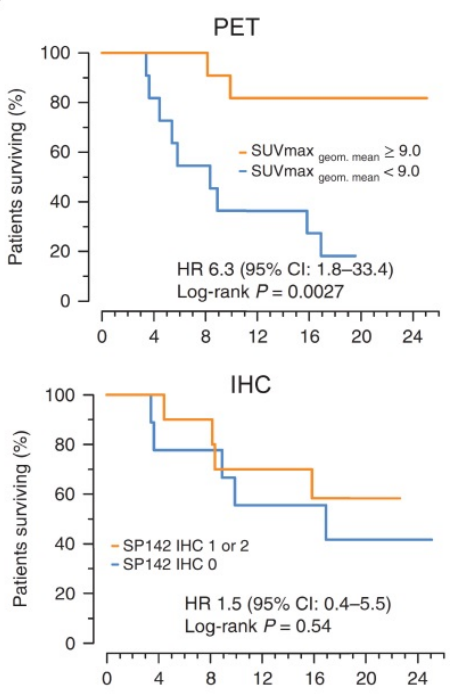

Figure 4. PET imaging of checkpoint molecules. (A) Schematic representing the major costimulatory and co-inhibitory molecules on a T-cell and their respective ligands that are expressed on either antigen presenting cells (APC) or tumor cells. (B) Representative images of PET images from bladder, non-small cell lung, and triple-negative breast cancer patients showing homogenous (i-v) and heterogenous (vi-viii) intratumoral labeling of PD-L1 using 89Zr-atezolizumab. Adapted from [1 12]. (C) Kaplan-Meier curves taken from patients in (B) treated with PD-L1 blockade using atezolizumab after PET imaging. PET imaging of PD-L1 expression shows a much higher power to predict response to PD-L1 blockade compared to a clinically available IHC protocol. Adapted from [112]. (D) Representative PET images of advanced non-small cell lung cancer patients infused with

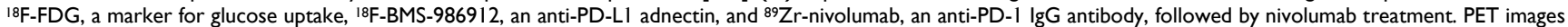
indicate the anti-PD-L1 adnectin can target and label PD-L1 expression in the tumor while ${ }^{89} \mathrm{Zr}$-nivolumab imaging indicates T cell infiltration in tumors expressing PD-L1. Adapted from [120].

\section{PD-LI}

PD-L1 can be expressed on cancer cells and immune cells and can directly interact with PD-1 molecules on T cells to inhibit T cell function. Studies have illustrated that expression of PD-L1 can be a predictive marker for response to PD-1/PD-L1 blockade in several cancers, including lung, breast, bladder, cervical, and gastric cancer [97]. Therefore, determining expression of PD-L1 could serve as a clinically relevant predictive and prognostic marker for PD-1/PD-L1 blockade. The current clinical protocol to continue with anti-PD-L1 immunotherapy is determined by immunohistochemical (IHC) staining of biopsied tumor sections for PD-L1 expression $[98,99]$. Although IHC is a well-established method in clinical practice, single biopsy samples, mis-sampling of the tumor, inability in obtaining adequate samples in patients with metastatic disease, variability in baseline expression, or the invasiveness of obtaining samples can all contribute to inconsistent and nonrepresentative results given extensive intraand inter-tumor heterogeneity. However, whole-body noninvasive imaging platforms, such as PET that provided entire body and tumor burden visualization, quantification, and localization of expression throughout the body is more comprehensive, informative, and prognostic compared to IHC.

To determine the feasibility of imaging PD-L1, a preclinical PET imaging study targeting PD-L1 was conducted in C57BL/6N mice implanted with PD-L1 expressing B16 melanoma and imaged with ${ }^{64} \mathrm{Cu}-$ NOTA-labeled anti-mouse PD-L1 IgG (clone 10F.9G2) [100]. A 2-fold increase in tracer uptake to the tumor was observed compared to the PD-L1 knockout control tumor 24 hours post-injection. To further establish the relevance of PD-L1 imaging, a preclinical study was conducted assessing PD-L1 expression upon treatment. It has been shown that radiation therapy (RT) synergizes with PD-1 blockade in preclinical melanoma models [101] and head and neck squamous cell carcinoma (HNSCC) [102]. To assess 
whether PD-L1 expression in the tumor increases in response to $\mathrm{RT}$, a subsequent study treated syngeneic murine head and neck squamous cell carcinoma (HNSCC) and melanoma tumor bearing mice with RT. The animals were injected with ${ }^{89} \mathrm{Zr}$-DFO-antimouse PD-L1 IgG (clone 10F.9G2) and imaged 24 hours later. PET imaging as well as ex vivo analysis revealed a 2 -fold increase in uptake of the targeted radiolabel in RT-treated tumors compared to untreated control, indicating PD-L1 induction can be visualized using PET imaging [103].

Preclinical studies have also utilized small proteins or single domain antibody fragments specific for PD-L1 due to their fast clearance from the blood and high tumor penetrance. For example, a nanobody against PD-L1 showed low background and high uptake in implanted melanoma tumors expressing PD-L1 after only 1 hour post-injection with peripheral organ uptake mainly limited to the kidney [104]. Several other studies have also developed nanobodies targeting PD-L1 for the purpose of PET imaging with similar imaging and biodistributional profiles [105107]. Additionally, an anti-PD-L1 affibody [108], which is an engineered three-helix bundle based on the 58 -residue $(6.5 \mathrm{kDa})$ scaffold of the IgG-binding $\mathrm{Z}$ domain of staphylococcal protein A, [109] has been used as a PET tracer to image PD-L1 expression. This tracer showed a 3-fold increase in signal in tumors, compared to non-PD-L1 expressing controls only 2 hours post-injection. In the same study, a synthetic macrocyclic peptide specific for PD-L1 showed a 5 -fold increase in signal in tumors relative to controls [109]. Ex vivo biodistribution studies revealed that tracer uptake is limited to the tumor, kidneys, and liver. Although these small proteins show promise due to their fast clearance, many preclinical studies have utilized clinically-approved anti-PD-L1 antibodies as PET imaging agents due to their easy transition into the clinical space.

Atezolizumab, an FDA-approved anti-PD-1 IgG antibody, has shown promising results in the treatment of urothelial carcinoma and NSCLC [95]. Preclinical studies using immune-compromised NSG mice with triple negative breast cancer (TNBC) tumor implants have shown ${ }^{111} \mathrm{In}$-labeled atezolizumab (SPECT imaging) [110] and ${ }^{64} \mathrm{Cu}$-atezolizumab (PET imaging) [111] uptake was 2-fold higher in PD-L1 high expressing cells compared to PD-L1 low expressing cells. Ex vivo biodistribution analysis revealed uptake of both tracers in the blood, spleen, kidney, liver, and lungs. This study facilitated the first-in-human clinical trials using ${ }^{89} \mathrm{Zr}$-labeled atezolizumab in patients with metastatic bladder cancer, non-small cell lung cancer (NSCLC), and TNBC [112]. Biodistribution studies indicated tracer uptake in intestines, kidney, and liver, reflecting locations of antibody metabolism and elimination as well as the spleen. They were able to visualize primary lesions and all main metastatic sites, especially from bladder cancer patients (Figure 4B). Furthermore, ${ }^{89} \mathrm{Zr}$-atezolizumab tumor uptake was highly correlated to patient response to atezolizumab as measured by RECIST categorization and KaplanMeier curves at a much more significant degree compared to two separate FDA-approved clinical IHC protocols for staining tumor tissues for PD-L1 (Figure $4 \mathrm{C})$, strengthening the role that non-invasive imaging can play as a predictive and prognostic marker for anti-PD-L1 immunotherapy. Avelumab, another FDA-approved anti-PD-L1 antibody used for treatment of urothelial and Merkle cell carcinoma, was recently tested in a preclinical setting as a targeting PET tracer [113]. Nude immune compromised mice bearing MDA-MB-231 breast cancer cells were injected with ${ }^{89} \mathrm{Zr}$-labeled avelumab and images were obtained 1,2, 3, and 6 days post-injection. PET images revealed tumor uptake but, unlike ${ }^{64} \mathrm{Cu}$-atezolizumab, high uptake was also observed in many other sites including the blood, lungs, femur, lymph nodes, spleen and liver. Ex vivo biodistribution analysis uncovered very high uptake in similar sites. This can be attributed to the fact that Avelumab, unlike Atezolizumab, cross-reacts with murine PD-L1, and thus murine organs that are PD-L1+ show specific uptake.

PD-L1 targeting antibodies have proven to be effective whole-body imaging agents translatable into the clinic, however, on-target off-tumor effects, such as PD-L1 staining of epithelial cells or macrophages in distant inflammatory regions, can increase background. To provide higher specificity, a study developed a PD-L1 "pro-antibody" [114]. Proantibodies, or probody, are antibodies that are only capable of binding to its antigen when a protease cleaves off the peptide mask covering the antigenbinding domain. The protease cleavage site can be engineered to be specific for any protease and, hence, the antibody can be site-specific depending on where in the body the protease is expressed. The first probody was developed targeting VCAM1 to target aortic plaques in a mouse model of atherosclerosis with a matrix metalloprotease 1 (MMP-1) cleavage site, a protease expressed in these plaques [115]. They found high staining of aortic plaques when using the probody with no staining in peripheral organs, unlike the parental control antibody that had lower aortic staining with high staining in the pancreas, lung, kidney, and intestine, indicating improved specificity when using the probody. This study laid the foundation for the development of an anti-EGFR 
probody, the first probody to treat cancer cells [116]. They found the probody had similar killing potential compared to the parental control but had a much better preclinical toxicology profile in cynomolgus monkeys. Higher specificity and lower toxicity of probodies are useful features for PET imaging agents. Therefore, a study utilized a newly developed probody, ${ }^{89} \mathrm{Zr}-\mathrm{CX}-072$, targeting PD-L1 as a PET imaging agent [114]. They found the probody had higher uptake in MDA-MB-231 implanted tumors compared to the parental non-probody antibody. More strikingly, they found much lower tracer uptake, both through imaging and ex vivo biodistribution studies, in the spleen as well as the skin, bone, and liver, indicating higher specificity and sensitivity. These results have led to the initiation of a clinical trial to test ${ }^{89} \mathrm{Zr}-\mathrm{CX}-072$ in patients with advanced or recurrent solid tumors or lymphomas (2016-002490-36).

Smaller molecules have also been tested in patients to image PD-L1 expression on tumors and predict response to immunotherapy. Adnectins, 10 $\mathrm{kDa}$ in size, are proteins developed based on the framework of the human 10th fibronectin type III domain $\left({ }^{10} \mathrm{FN} 3\right)$. The ${ }^{10} \mathrm{FN} 3$ framework is structurally similarity to antibody variable domains and are suitable for PET imaging owing to their small size, favorable pharmacokinetic properties, and a non-toxic non-immunogenic profile [117]. An adnectin against PD-L1 has been developed and tested in a preclinical and clinical setting. Preclinical studies showed that anti-PD-L1 radiolabeled adnectins had high signal to background ratio and good bio-distributional properties, with uptake mainly in the tumor, liver, and kidneys [118,119]. A ${ }^{18}$ F-labeled adnectin targeting human PD-L1 (BMS-986192), has recently been tested in non-small lung cancer patients in a first-in-human clinical trial, confirming a correlation between tumor uptake of the tracer and both PD-L1 expression using IHC and clinical response to Nivolumab, a PD-1 blockade therapy (Figure 4D) [120]. Trials in melanoma patients are currently ongoing (NCT03520634).

In conclusion, these studies have illustrated the utility of whole-body imaging of PD-L1. Two first-in-human clinical studies determined significant correlation between PD-L1 detection using PET imaging and response to immunotherapy. Due to the advantage of imaging the entire tumor burden including all metastatic lesions as well as detecting heterogeneous expression of PD-L1 within each tumor, PET imaging is a superior predictive tool versus IHC staining of tumor biopsies. Hence, imaging whole-body PD-L1 expression shows immense promise in not only characterizing the entire tumor burden, but also helping with decision making and patient management, as well as assessing therapeutic response and clinical outcome.

\section{PD-1}

PD-1 is an immune checkpoint molecule expressed on lymphocytes including $\mathrm{T}$ cells [121]. Anti-PD-1 blocking antibodies, such as pembrolizumab and nivolumab, have shown promising results in the treatment of several advanced malignancies such as metastatic melanoma, non-small cell lung cancer, and Hodgkin's lymphoma, among others [122]. Many findings have determined tumor infiltrating T-cells expressing PD-1 are functionally impaired, with PD-1 blockade restoring activity, suggesting noninvasive imaging of PD-1 expression and localization into the tumor can be a clinically relevant predictive marker for anti-PD-1 therapy.

Several preclinical PET studies using murine cancer models were performed to assess the feasibility of imaging PD-1-expressing cells. Animals implanted with B16 melanoma tumors were imaged with a ${ }^{64} \mathrm{Cu}-$ DOTA-mouse anti-PD-1 IgG (clone J43) PET tracer that was able to detect the tumor 48 hours postinjection with noticeable tracer uptake in the blood, spleen, kidney, and liver [123]. Another study used a ${ }^{64} \mathrm{Cu}-\mathrm{NOTA}$-mouse anti-PD-1 IgG2a (RMP1-14) PET tracer and found similar results with high uptake in the tumor, blood, liver, kidney and spleen 24 hours post-injection [100]. Given that these PET imaging studies used murine antibodies and cancer cells, subsequent preclinical studies used clinically-relevant human targeting agents and models.

Several studies have used radiolabeled pembrolizumab and nivolumab, FDA-approved antihuman PD-1 IgGs, for PET imaging in humanized mouse models. One study assessed the pharmacokinetic and biodistribution of ${ }^{89} \mathrm{Zr}$-labeled pembrolizumab and found that immunecompromised NSG mice engrafted with human peripheral blood mononuclear monocytes (PBMC) showed higher tracer uptake in the liver and salivary gland 7 days post-injection compared to nonengrafted mice [124]. Ex vivo immunofluorescence (IF) staining-verified $\mathrm{PD}^{+} \mathrm{T}$-cells were present in the salivary glands, which is a hallmark of graft vs. host disease and other autoimmune diseases [125]. A subsequent study extended these experiments to include human A375 melanoma implanted in NOD-SCID immunocompromised mice engrafted with human PBMCs. The study found that uptake of both ${ }^{89} \mathrm{Zr}$ - and ${ }^{64} \mathrm{Cu}$-labeled pembrolizumab in the tumor was 2 -fold higher compared with nonengrafted mice [126]. Biodistribution analysis 
revealed that ${ }^{89} \mathrm{Zr}$-pembrolizumab had a lower uptake in peripheral organs compared to ${ }^{64} \mathrm{Cu}$ pembrolizumab while maintaining high uptake in the tumor, kidney, and liver. These preclinical studies led to the initiation of clinical trials using ${ }^{89} \mathrm{Zr}-$ pembrolizumab to image patients with NSCLC or metastatic melanoma (NCT02760225, NCT03065764). Additionally, a study utilizing PET imaging with ${ }^{89} \mathrm{Zr}$-nivolumab in NOD-SCID mice implanted with A549 human NSCLC cells 7 days post-injection showed that tracer uptake by the tumor was $\sim 3$-fold higher in mice reconstituted with human PBMCs compared to non-grafted mice, a better signal compared to ${ }^{89} \mathrm{Zr}$-pembrolizumab [127]. Ex vivo biodistribution analysis revealed high uptake of the tracer in the tumor, salivary glands, and spleen, a similar profile to that of ${ }^{89} \mathrm{Zr}$-pembrolizumab. ${ }^{89} \mathrm{Zr}$ nivolumab was also utilized in a clinical study with advanced NSCLC patients in parallel with ${ }^{18} \mathrm{~F}-\mathrm{BMS}-$ 986192 (anti-PD-L1 adnectin) [120]. PET imaging revealed $\mathrm{T}$-cell infiltration into tumors that were PD-L1+, indicating a correlation between PD-L1 and PD-1 tracer uptake (Figure 4D). Furthermore, NSCLC cancer patients responding to nivolumab had 1.5-fold increase in ${ }^{89} \mathrm{Zr}$-nivolumab uptake in the tumor compared to non-responders, indicating PD-1 imaging can serve as a predictive tool for response to immunotherapy.

While anti-PD-L1 imaging agents mainly label PD-L1-expressing tumor cells, PET imaging using anti-PD-1 targeted agents will label exhausted and activated $\mathrm{T}$ cells. Preclinical studies determined the feasibility of imaging $\mathrm{T}$ cells infiltrating into tumors, while a clinical study correlated tracer uptake in the tumor to anti-PD-1 therapy response. While these findings are appealing and promising, some concerns remain. Although PD-1 is mainly associated with activated T cells, PD-1 expression has been observed on activated B cells [128] and macrophages [129], indicating that tracer uptake cannot be specifically attributed to $\mathrm{T}$ cells. Therefore, to solidify PD-1 expression as a predictive or prognostic marker for immunotherapy, further PET imaging clinical studies are needed.

\section{CTLA-4}

CTLA-4, similar to PD-1, is an inhibitory molecule whose expression is induced on cytotoxic $\mathrm{T}$ cell upon activation (94) and is constitutively expressed on Treg cells [130]. Similar to PD-1 blockade, CTLA-4 blockade can result in autoimmune-related adverse effects in many patients (130) and, thus, there is an urgent need to develop methods to assess or even predict patient response to CTLA-4 blockade therapies. Clinical studies using patient samples have correlated CTLA-4 expression of tumor-infiltrating $\mathrm{T}$ cells to ipilimumab response in melanoma using whole-exome RNA sequencing, and in NSCLC patients through IHC staining of tumor sections [132,133]. Thus, imaging of CTLA-4 expressing $\mathrm{T}$ cells can be a predictive marker for response to CTLA-4 blockade. Furthermore, monitoring the trafficking of exhausted and/or activated T cells as well as Treg cells in the TME can provide further insight into the behavior of these immune cells. Therefore, PET imaging of CTLA-4 can be both clinically relevant for patients and helpful for expanding our understanding of immunological processes.

An early preclinical PET imaging study used a ${ }^{64} \mathrm{Cu}$-DOTA-anti-murine CTLA-4 IgG2a antibody to visualize T cells in a murine CT26 colon cancer model in BALB/C mice as to evaluate the prospect of imaging CTLA-4 [134]. Ex vivo biodistribution studies revealed a modest yet significant increase ( 1.3-fold) in tracer uptake in the tumor compared to IgG control, as well as uptake in the liver and kidney. CTLA-4 expression in tumors was verified to be specific to T-cells and not the tumor cells using RT-PCR, indicating that the PET tracer signal from the tumor is specifically due to tumor-infiltrating $T$ cells. Since the tracer signal in the murine cancer model was not ideal, a subsequent PET imaging study was performed using ipilimumab, a FDA-approved antihuman CTLA-4 IgG1, in humanized mice. This study used ${ }^{64} \mathrm{Cu}$-NOTA-ipilimumab as well as the ${ }^{64} \mathrm{Cu}$ NOTA-ipilimumab-F( $\left(\mathrm{bb}^{\prime}\right) 2$ fragment in NOD-SCID mice engrafted with human PBMCs [135]. As expected, both tracers successfully labeled activated T-cells in the salivary glands with ipilimumab-F $\left(a b^{\prime}\right) 2$ clearing at a faster rate than the full-sized antibody, while ex vivo biodistribution studies showed high uptake in expected sites such as the liver, spleen, and kidney. Thus, this study verified ipilimumab as a valid targeting PET imaging agent that tracked human $\mathrm{T}$ cells to the predicted organ site. Although no study has been conducted using human cancer cells implanted in mice engrafted with human PBMCs, the available studies cleared the path for a clinical trial currently being conducted to assess the uptake and biodistribution of ${ }^{89} \mathrm{Zr}$-ipilimumab in metastatic melanoma patients (NCT03313323).

Treatment with CTLA-4 blockage has shown immense promise in melanoma patients yet only a portion of patients respond and over $80 \%$ of patients experience some level of adverse effect [136]. Thus, there is a need to identify patients who may respond to CTLA-4 blockade. Preclinical studies are promising in that they verified CTLA-4 as an imaging marker of activated $\mathrm{T}$ cells. However, preclinical or clinical 
studies have yet to determine its predictive or prognostic ability. Therefore, further studies need to be conducted to ascertain the clinical relevance of imaging CTLA-4.

\section{LAG-3}

CD223, known as the "lymphocyte activation gene-3" (LAG-3), is another checkpoint molecule present on the surface of T cells [137]. Several clinical trials targeting LAG-3 for cancer therapy are ongoing [137]. While much progress has been made in targeting LAG-3 for therapy, imaging of LAG-3 is an emerging field. A recent study developed several antiLAG-3 nanobodies and used ${ }^{99 \mathrm{mT}} \mathrm{Tc}$ labeled nanobodies for in vivo imaging [138]. Animals implanted with murine TC-1 lung epithelial cells, engineered to overexpress LAG-3 were used to establish the imaging. A high tumor-specific signal was observed 1 $\mathrm{h}$ post-injection of the radiolabeled nanobody. There is still a need for studies to assess whether LAG-3 imaging can be used to detect tumor-infiltrating lymphocytes and predict the response to LAG-3 or other checkpoint blockades.

Taken together, imaging checkpoint molecules have shown great promise in providing valuable information on the TME, with several imaging probes already moved into the clinical phase. Further studies are needed to better understand how imaging checkpoint molecules can help to make informed decisions on best treatment strategies.

\section{Imaging engineered $T$ cells}

Chimeric antigen receptor (CAR) $\mathrm{T}$ cells are genetically modified T-cells that express a synthetic receptor capable of binding to a target. The binding to the target cells will result in activation, expansion, and, ultimately, killing of the target cells. CAR T cells have shown promising responses against a variety of blood-born malignancies. For example, CD19-targeting CAR T cells have shown outstanding response in patients with large B cell lymphoma or acute lymphoblastic leukemia (ALL) [139,140]. Notwithstanding these encouraging results, responses remain heterogeneous among patients. Many patients show a partial or no response to treatment. In some cases, there is a lack of CAR T cell persistence in the patient [141]. A robust prognostic method is needed to assess or even predict the response to CAR T cell treatment. Current methods to assess effectiveness of CAR T cells include detection of cytokines [142], digital PCR analysis [143], or flow cytometry on blood samples [144]. However, none of these methods provide as much anatomical scope as whole-body imaging techniques such as PET. Therefore, noninvasive imaging of CAR T cells can prove to be a useful prognostic tool. To accomplish this, studies have utilized two different approaches to image CAR $\mathrm{T}$ cells (Figure 5A): (i) ex vivo radiolabeling of engineered $\mathrm{T}$ cells or (ii) in vivo radiolabeling of engineered $\mathrm{T}$ cells through utilization of reporter genes.

\section{Ex vivo labeling}

Direct labeling of immune cells isolated from patients is a commonly used labeling technique in which immune cells are incubated ex vivo with an imaging agent before being adoptively transferred into the patient. Early efforts in this regard involved MRI-based detection of immune cells. One such report demonstrated high resolution data of tumor-infiltrating cytotoxic $\mathrm{CD}^{+} \mathrm{T}$ cells using high-field MRI and superparamagnetic iron oxide nanoparticles [145]. This labeling strategy enables simple, rapid, and specific labeling of any chosen immune cell of interest, including CAR T cells. These MRI-based approaches are also detailed in a prior review [146]. In this review we focus on nuclear imaging techniques, which are currently considered to have the highest chance of clinical translation.

Ex vivo cell labeling relies on the use of ionophore chelators to carry radioisotopes across the plasma membrane and maintain cell viability. The first instance of ex vivo labeling was by direct incubation of $99 \mathrm{~m} \mathrm{Tc}$ with human monocytes to monitor chemotaxis [147]. However, only 50\% cellular viability was observed post-labeling. In order to increase viability while maintaining labeling efficiency, ionophore chelators, such as 8-hydroxyquinoline (oxine) or hexamethylpropyleneamine (HMPAO) are used. Labeling of granulocytes with ${ }^{111}$ In-oxine and ${ }^{99 \mathrm{~m} T \mathrm{c}-H M P A O}$ revealed $98 \%$ viability with $73 \%$ and $44 \%$ labeling efficiency, respectively. These studies established the applicability of ionophore chelators, which are used in ex vivo CAR T cell imaging studies. A study utilized ${ }^{89} \mathrm{Zr}$-oxine for labeling anti-IL13Ra2 CAR $\mathrm{T}$ cells that targeted glioblastoma multiforme (GBM) cells [148]. They found labeling efficiency of CAR T cells was $75 \%$ while labeled cells retained more than $60 \%$ of the ${ }^{89} \mathrm{Zr}$ after 6 days in vitro. CAR T cells delivered intraventricularly were detectable by PET at least 6 days post-injection within intracranial patient-derived GBM tumors implanted in NSG mice with no effect on CAR T cell-mediated tumor killing (Figure 5B), indicating that ex vivo labeling maintains CAR $\mathrm{T}$ cell function and PET tracer signal in vivo throughout a relevant timeframe.

While 8-hydroxyquinoline is an established ionophore chelator for ${ }^{89} \mathrm{Zr}$, a novel labeling agent, ${ }^{89} \mathrm{Zr}$-labeled- $p$-isothiocyanato-benzyl-desferrioxamine 
( $\left.{ }^{89} \mathrm{Zr}-\mathrm{DBN}\right)$, was developed. This PET tracer covalently binds to solvent-exposed lysine residues resulting in higher cellular viability post-labeling and, unlike 8-hydroxyquinoline, no effluxion [149]. In a recent study, this agent was used to label anti-CD19 CAR Jurkat cells ex vivo with $98 \%$ radiolabeling efficiency and detectable signal in vivo. However in this model, CAR T cell trafficking into the tumor site was not observed [150]. This could be due to the use of Jurkat leukemia cells, instead of engrafted human $\mathrm{T}$ cells, as well as subcutaneous injection of Raji cancer cells, a Burkitt's lymphoma line, rather than a relevant human solid tumor cell line. Therefore, further studies with appropriate CAR T cells and mouse models are needed to verify the feasibility of using ${ }^{89} \mathrm{Zr}-\mathrm{DBN}$ as an ex vivo imaging agent.

T-cell receptors (TCR) are an attractive target for ex vivo labeling due to their constant recycling and turnover, resulting in internalization and accumulation of the PET tracer. A study was able to take advantage of this phenomenon by labeling the chicken-ovalbumin-specific TCR-transgenic $\mathrm{CD}^{+} \mathrm{T}$ cells (cOVA-TCRtg-TH1) using a ${ }^{64} \mathrm{Cu}$-labelled TCR-Ova-specific antibody (KJ1-26) to study the migration pattern of antigen-specific $\mathrm{T}$ cells. The radiolabeled antibody was incubated with cells for 30 min and internalization was allowed to proceed for 24 h. The study illustrated that this approach resulted in low radiation-induced cellular damage and low radiotracer efflux [151]. The radiolabeled $\mathrm{T}$ cells yielded high contrast PET images when injected into animals and their migration was successfully tracked to the pulmonary and perithymic lymph nodes upon OVA-induced airway delayed-type hypersensitivity reaction.

A CAR T cell Imaging Approaches

\begin{tabular}{|l|l|l|}
\hline \multicolumn{2}{|c|}{ Ex vivo labeling } \\
\hline Advantages: & - Simple protocol & - In vivo labeling \\
\hline Disadvantages: & - Time-limited imaging window & Potential immunogenicity \\
\hline
\end{tabular}

B

$$
\begin{aligned}
& \text { Ex vivo approach } \\
& \text { 89Zr-oxine }
\end{aligned}
$$
Hours post injection

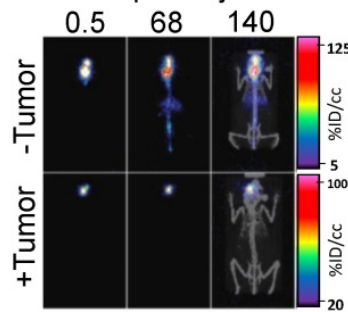

In vivo approach

HSV-TK $+{ }^{18} \mathrm{~F}-\mathrm{FHBG}$
$P S M A+{ }^{18} F-D C F P y L$

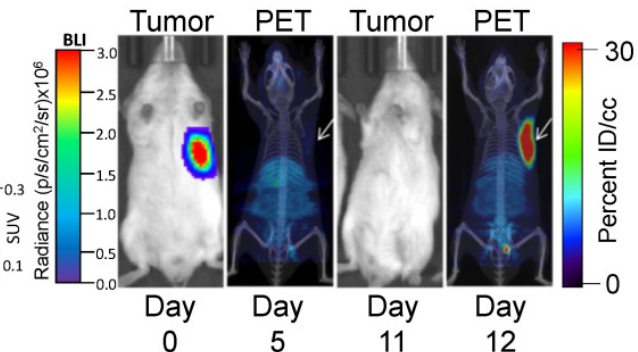

Figure 5. Imaging Engineered T Cells. (A) Schematic of different approaches utilized for imaging CAR T cells. Two different approaches are commonly used to label, noninvasively track, and monitor engineered T cells. The ex vivo approach involves direct use of the PET radiotracer on the engineered T cell, either through binding of the tracer to proteins on the plasma membrane or through passive transport across the plasma membrane using an ionophoric chelator. The advantage to this method is that it is well-established, simple, and easy to conduct, however it requires same-day imaging due to dilution of the tracer upon $\mathrm{T}$ cell expansion. The in vivo approach utilizes the expression of a reporter gene in the engineered T cell and, subsequently, infusion of the PET radiotracer specific to the reporter in the patient at a later timepoint. The advantage to this approach is the ability to image at any timepoint. (B) Examples of both CAR T cell imaging approaches. An ex vivo labeling approach (left) illustrates CAR T cells localizing to the GBM tumor even after $140 \mathrm{~h}$ after adoptive transfer. Adapted from [148]. An in vivo labeling approach using the HSV-TK reporter system (center) shows the infused CAR T cells localizing a resected tumor [ $I$ ] and trafficking to a distal tumor site [2]. Adapted from [154]. A preclinical in vivo labeling approach using the PSMA reporter system (right) illustrates CAR T cell infiltration into the tumor. Adapted from [168]. 
All together, these studies have developed ex vivo labeling as a simple technique to label and monitor immune cells. Because CAR $\mathrm{T}$ cells are produced ex vivo and adoptively transferred back into the patient, ex vivo labeling is a straightforward addition to a clinical protocol that does not require any extra invasive or preparatory steps for the patient. Therefore, ex vivo labeling of CAR T cells is suitable for incorporation into clinical practice. However, the major limitation of this technique is the timepoint of imaging after infusion due to the decay and effluxion rate of the PET tracer. Thus, the time required for CAR T cells to migrate into the tumor site needs to be appropriate for the decay and effluxion rate of the PET tracer. Furthermore, CAR T cells expand upon activation, which causes dilution of the radiotracer resulting in an overall short half-life of ex vivo labeling approaches. Macrophages can also phagocytose labeled cells or cellular debris and migrate, causing nonspecific PET signals. Therefore, further preclinical studies are needed to determine the clinical feasibility of ex vivo labeling of CAR T cells.

\section{In vivo labeling}

Indirect labeling of CAR T cells using a reporter gene is an imaging strategy that can overcome the shortcomings of ex vivo labeling. A reporter gene can mark CAR T cells enabling the cell and its progeny to be distinguished from other cells after they undergo migration, homing and expansion, making noninvasive sequential imaging of cell trafficking possible in vivo. Established reporter genes include herpes simplex virus thymidine kinase (HSV-TK), human norepinephrine transporter (hNET), sodiumiodide symporter (hNIS), and others [152].

The HSV-TK has been the most extensively used PET reporter gene system. Patient-derived cytotoxic lymphocytes can be transduced with both the CAR and HSV-TK. Upon infusion of the CAR $T$ cells expressing HSV-TK, radiolabeled penciclovir, an inhibitor of HSV-TK, can be administered intravenously, which will then target the CAR T cells. The strength of this system is the specificity of the reporter/inhibitor and the freedom to inject the targeted imaging agent at any timepoint. This system shows high specificity and low background, especially when using a mutant HSV-TK with higher affinity for penciclovir [153]. This reporter system was used in a GBM patient using a CAR $\mathrm{T}$ cell targeting IL13Ra2 [154], an adoptive cell therapy that has passed phase I clinical trials (157). The study was not only able to image CAR T cells in the resected tumor but was also able to label and monitor CAR T cells that trafficked to an adjacent non-resected GBM tumor (Figure 5B). In a follow up study with six additional GBM patients, intraventricular injected CAR T cells expressing HSV-TK were found to be effectively imaged in five patients exhibiting a two-fold increase signal compared to baseline while one patient exhibited high background due to a rich vascular supply with a disrupted blood-brain tumor barrier [156].

A concern that exists with the HSV-TK reporter system is its potential immunogenicity. Clinical studies have shown that CAR $\mathrm{T}$ cells expressing HSV-TK are safe and functionally intact [157] but long term studies are needed. To circumvent this potential issue, human reporter genes, such as sodium iodide symporter (hNIS) [158], norepinephrine transporter (hNET) [159], and somatostatin receptor 2 (SSTR2) [160] have been used to label CAR $\mathrm{T}$ cells. The advantage of hNIS is that it is non-immunogenic, not internalized, and is only functional in living cells [161], while a well-established radioisotope,

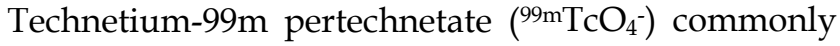
used in clinical nuclear medicine can be used to monitor the effect of therapy. However, hNIS is expressed in many normal epithelial tissues and predominantly expressed in many carcinomas [162]. SSTR2 is a potentially more suitable reporter marker due to its limited baseline expression in normal tissues and the availability of clinically approved radiotracers such as ${ }^{68} \mathrm{Ga}$-octreotide analogues ( ${ }^{68} \mathrm{Ga}$-DOTATOC [163] and $\left.{ }^{68} \mathrm{Ga}-D O T A T A T E ~[164]\right)$. However, SSTR2 internalizes upon interaction with ligands, reducing imaging sensitivity, and is expressed on immune cells, leading to impaired $\mathrm{T}$ cell function upon SSTR2 ligation with ${ }^{90}$ Y-DOTATOC [165].

A recent clinically relevant CAR $\mathrm{T}$ cell PET imaging modality was developed utilizing PSMA and 2-(3-(1-carboxy-5-[(6-[18F]fluoro-pyridine-3-carbonyl)amino]-pentyl)-ureido)-pentanedioic acid $\left({ }^{18} \mathrm{~F}-\right.$ DCFPyL). PSMA is a cell surface protein whose expression is largely limited to the prostate gland [166], making it an ideal reporter candidate. ${ }^{18} \mathrm{~F}-\mathrm{DCFPyL}$ is a highly sensitive and selective probe targeting PSMA with low off-target staining, providing high contrast clinical images [167], and is currently undergoing phase III clinical trial in patients with suspected recurrence of prostate cancer (NCT03739684). This PET imaging system was able to label T cells co-expressing anti-CD19 CAR and PSMA with high sensitivity in vitro and in vivo and visualized CAR $\mathrm{T}$ cell infiltration into primary and metastatic Nalm6 tumors (Figure 5B). Interestingly, this study revealed no correlation between CAR $T$ cell prevalence in peripheral blood, which is the current clinical practice, versus CAR $\mathrm{T}$ cell infiltration visualized by PET, indicating CAR T cell presence in 
the peripheral blood may not accurately reflect therapeutic effectiveness and that PET may be a more clinically relevant prognostic tool [168].

These studies demonstrate the power of reporter systems to label, track, and monitor CAR T cells. Unlike ex vivo labeling strategies, in vivo labeling approaches allow for PET imaging at any timepoint after CAR T cell infusion and is not subject to signal loss due to CAR $\mathrm{T}$ cell persistence and expansion. Reporter genes, such as the PSMA and ${ }^{18} \mathrm{~F}-\mathrm{DCFP} y \mathrm{~L}$ imaging system, can verify trafficking of CAR T cells to tumor and metastatic sites as well as provide better prognostic power compared to serial assessment in the peripheral blood. Taken together, PET imaging of CAR T cells using reporter genes is highly applicable in the clinic and shows promise as a prognostic tool.

\section{Conclusion and future directions}

While immunotherapy is increasingly being used to treat cancer, there remains a need for methods to adequately characterize the entire tumor burden, assess the response to treatment, and predict which patients are likely to benefit from it. Similarly, there is a need to better assess the presence of many cancer-associated markers (i.e., HER2 or PSMA), which are predictive of response to targeted therapies. The current gold standard procedure for tumor analysis, a tumor biopsy followed by immunohistochemistry, is invasive and has many limitations. Stained samples reflect a small portion of the tumor, and are often unrepresentative of the remainder of the primary tumor or its metastatic lesions [18]. Whole body imaging techniques such as PET or SPECT, however, are noninvasive and enable visualization of the distribution markers across the entire tumor burden.

Monitoring the dynamics of immune cells in the TME can help assess or even predict the response to immunotherapy. A number of methods to detect immune cell subsets have been developed, including several that have progressed into clinical trials. These include small molecule probes, as well as antibody and antibody fragments. We can anticipate the clinical translation of tracers for imaging other immune cell markers such as CD11b for myeloid cells and costimulatory molecules such as ICOS for activated T cells in the future.

It is worth noting that nanoparticle-based contrast agents have also been developed to monitor specific immune cell subsets by MRI. Macrophages preferentially phagocytose the iron oxide nanoparticles, allowing for specific contrast enhancement in tumors occupied by TAMs [169]. Because of its selectivity for macrophages, ferumoxytol can also be used to assess the macrophage-mediated anti-tumor response. This is particularly interesting in the context of anti-CD47 therapy, where macrophages are activated to phagocytose CD47-expressing cancer cells. In one study, ferumoxytol nanoparticles were successfully used to assess the response to anti-CD47 therapy in a preclinical model of osteosarcoma [170]. Nanoparticle-based contrast agents will likely find increasing use as tools to assess the response to immunotherapy and monitor immune cell subsets.

While most studies have focused on imaging of immune cells, imaging of relevant immune cytokines and secreted molecules holds promise as well for assessing the tumor immune status. Imaging of IFN- $\gamma$ and granzyme $B$ have been successful in assessing the response to immunotherapy in animal models $[28,53]$. There is a need to develop a larger number of cytokine-imaging strategies that can reliably reflect the immune status of the TME in preclinical models and eventually in patients. There are small molecules binding to IL-2 that can potentially be repurposed as PET tracers [171,172]. There are still many important targets that have not been imaged in preclinical studies, and we need to better understand how their dynamics correlate with treatment outcome. For example, the presence of chemokines such as CXCL9, CXCL10, and CCL5, have been shown to have prognostic value for the response to immunotherapy [78]. Whether imaging such cytokines holds prognostic value remains to be studied. Radiolabeled antibodies or antibody fragments, small molecules, or their cognate receptors, can be useful for imaging such targets.

CAR T cell therapy has been unable to effectively treat solid tumors, which is attributed to the immuno-suppressive environment of many solid tumors. Whole-body imaging of CAR $\mathrm{T}$ cells can present a method for assessing response. Each of the two methods used for imaging CAR $\mathrm{T}$ cells, ex vivo and in vivo labeling, provides advantages and disadvantages. Given that $\mathrm{T}$ cells need to be extracted from patients, forced to express the CAR, then adoptively transferred back into patients, labeling the cells ex vivo is a simple addition to a clinical protocol. However, due to the dilution and efflux of the imaging agent as CAR T cells expand and persist, PET imaging is time restricted. Yet, reporter genes can be expressed in conjunction with the CAR allowing for imaging to be conducted at any timepoint after treatment. Currently, no ex vivo labeling is in the clinical phase and there are limited preclinical studies. However, imaging using reporter genes, such as HSV-TK, have been used in the clinic with GBM patients, where CAR T cell tumor infiltration as well as trafficking to distant tumors were observed $[27,154]$. Additionally, preclinical studies have 
established many other reporter genes, including the promising PSMA and ${ }^{18} \mathrm{~F}-\mathrm{DCFPyL}$ reporter system in CAR T cells [168]. These studies indicate that in vivo labeling of CAR T cells using reporter genes presents a better method to visualize CAR T cells. A clinical limitation to this method is the potential immunogenicity of the reporter. Although HSV-TK has been shown to be safe [157], long term studies are necessary to assess the immunogenicity of this reporter construct. The human reporter genes SSRT2 and NIS are much less likely to be immunogenic, however they are expressed on other tissues. The most promising preclinical reporter gene is PSMA due to its lack of immunogenicity, lack of basal expression throughout the body excluding the prostate, and easy detection using a high affinity, specific radioisotope. Most strikingly, the study indicated that using PET imaging to assess CAR T cell localization to the tumor lesion is a better indicator of response compared to CAR $\mathrm{T}$ cell presence in the blood, indicating a clinical advancement for monitoring CAR $\mathrm{T}$ cells using noninvasive whole body imaging. Therefore, these clinical and preclinical PET imaging studies of CAR $T$ cells using reporter systems provide great promise for monitoring clinical response of CAR T cell treatment in the future.

Immune checkpoint blockade therapies, such as PD-1, PD-L1 and CTLA-4 blockade have revolutionized the treatment of cancer. Excitingly, atezolizumab, an FDA-approved PD-L1 blocking antibody, labeled with ${ }^{89} \mathrm{Zr}$ has the ability to noninvasively visualize the primary tumor and distant metastatic sites as well as predict the response to atezolizumab treatment at a higher power compared to IHC [112]. Although using the same full-sized antibody therapy as a PET imaging agent is highly appropriate, several disadvantages exist. Firstly, a full-sized antibody has a long half-life (3 weeks) and, therefore, a patient is exposed to radiation for a longer period. Secondly, due to its large size, antibodies have low penetrance into the tumor and stays present within circulating blood for a long period of time. This means that patients cannot be imaged the same day upon infusion with the PET tracer. To alleviate these issues, smaller targeted agents such as nanobodies [173], adnectins [120], or peptides $[109,174]$ targeting PD-L1 are being tested in clinical trials to assess their safety and efficacy profiles. These agents have a short half-life, higher penetrance, and faster clearance from circulation, therefore allowing for same day imaging with less radiation exposure to the patient. Hence, these smaller agents are more clinically viable if they can provide the same predictive power as shown with ${ }^{89} \mathrm{Zr}$-atezolizumab.
Unlike imaging PD-L1, PD-1 and CTLA-4 PET imaging are used to assess and monitor $\mathrm{T}$ cell activation. This may provide a prognostic tool to determine if PD-1 or CTLA-4 therapy promotes T cell activation and infiltration into the tumor. Further preclinical and clinical studies are necessary to assess their prognostic value. Overall, PET imaging of checkpoint molecules shows great potential in predicting and monitoring patient response to immunotherapy. Further clinical trials can shed light onto the potential scope, such as tumor types, of checkpoint PET imaging. Furthermore, whole-body imaging of immune checkpoints in patients can determine dynamics in checkpoint molecule expression while on immunotherapy and provide insight into the mechanism of resistance or relapse to immunotherapy. Hence, PET imaging of checkpoint molecules provides great utility in both clinical and preclinical applications.

Of note, and in line with the advancement of noninvasive imaging approaches, significant advances are being made in the realm of multifunctional "nanotheranostics" to develop new imaging and therapeutic approaches. Recent nanotheranostic therapeutic advancements include the development of a new liquid brachytherapy approach via novel cationic micelle and liposome formulations [175], and the use of cross-linked iron oxide nanoparticles conjugated to azademethylcolchicine (CLIOT-ICT) as a method to eradicate a subpopulation of quiescent glioblastoma initiating cells [176]. Another recent theranostic advancement is the analysis of cancer cells by ultrasensitive dark-field imaging using gold nanoparticle bouquets [177]. With a realistic mind regarding a timeline for clinical translation, the above-mentioned approaches may need some additional time to achieve regulatory approval, but represent examples of the next generation of multi-functional agents that are certainly in the pipeline, most of which also make use at least in part of radioimaging or radiotherapy.

Overall, we expect that the efforts outlined in this manuscript will draw the excitement of the field and point to new targets for noninvasive imaging. We anticipate that future mechanistic studies in cancer biology and immunology will reveal novel biological mechanisms, which will point to further potential new targets for imaging. This trend is only expected to grow. Ultimately, the development and clinical translation of such PET tracers will help characterize the entire tumor burden, stratify responders from nonresponders, make informed therapeutic decisions, and assess therapeutic response (or lack thereof) to the benefit of many patients. 


\section{Abbreviations}

1-L-18F-FETrp: 1-(2-18F-fluoroethyl)-L-tryptophan; ${ }^{10} \mathrm{FN} 3:$ 10th fibronectin type III domain; 18F-CFA: 2-chloro-2'-deoxy-2'-[18F]fluoro-9-b-Darabinofuranosyl-adenine; $\quad{ }^{18} \mathrm{~F}-\mathrm{DCFPyL}: \quad 2-(3-(1-$ carboxy-5-[(6-[18 $\mathrm{F}]$ fluoro-pyridine-3-carbonyl)-amino $]$ -pentyl)-ureido)-pentanedioic acid; ${ }^{18 F-F A C: ~ 1-(2 '-~}$ deoxy-2'-[18F]fluoroarabinofuranosyl) cytosine; ${ }^{18} \mathrm{~F}-\mathrm{FB}: \mathrm{N}-\left(4-{ }^{18} \mathrm{~F}\right]$ fluorobenzoyl); ${ }^{18} \mathrm{~F}-\mathrm{FDG}$ : 2-deoxy-2[fluorine-18]fluoro-D-glucose; ${ }^{89} \mathrm{Zr}-\mathrm{DBN}$ : ${ }^{89} \mathrm{Zr}$-labeled$p$-isothiocyanato-benzyl-desferrioxamine; ACT: adoptive cell therapy; ALL: acute lymphoblastic leukemia; AraG: 9-( $\beta$-D-Arabinofuranosyl)guanine; BCMA: B cell maturation antigen; CAR: chimeric antigen receptor; cOVA-TCRtg-TH1: chickenovalbumin-TCR-transgenic TH1 cells; CT: computed tomography; CTLA-4: cytotoxic lymphocyte antigen-4; dCK: deoxycytidine kinase; FcRn: neonatal Fc receptor; FLT: fluorothymidine; GBM: glioblastoma multiforme; GvHD: graft versus host disease; HMPAO: hexamethylpropyleneamine; hNET: norepinephrine transporter; hNIS: sodiumiodide symporter; HNSCC: head and neck squamous cell carcinoma; HSV-TK: herpes simplex virus - thymidine kinase; IDO: indoleamine 2,3dioxygenase; IF: immunofluorescence; IFN-ү: interferon gamma; IHC: immunohistochemistry; IL-2: Interleukin-2; irAEs: immune-related adverse events; MMP-1: matrix metalloprotease-1; MMR: macrophage mannose receptor; MRI: magnetic resonance imaging; NK: Natural Killer; NOD/SCID: non-obese diabetic/severe combined immunodeficiency; Oxine: 8-hydroxyquinoline; PBMC: peripheral blood mononuclear monocytes; PD-1: programmed cell death protein-1; PEG: polyethylene glycol; PET: positron emission tomography; PSMA: prostate specific membrane antigen; RT: radiation therapy; scFv: single chain variable fragment; SPECT: singlephoton emission computed tomography; SSTR2: somatostatin receptor 2; STING: stimulator of interferon genes; TCR: T cell receptor; TILs: tumorinfiltrating-lymphocytes; TK1: thymidine kinase 1; TME: tumor microenvironment; TNBC: triple negative breast cancer; TNF-a: tumor necrosis factor alpha; TPA: 12-O-tetradecanoyl-phorbol-13-acetate.

\section{Acknowledgements}

Funding was provided by the American Cancer Society postdoctoral fellowship (T.R.), 1K22CA226040 (M.R.), and the Dana-Farber Cancer Institute Innovation Research Fund Basic Research Grant (M.R).

\section{Competing Interests}

The authors have declared that no competing interest exists.

\section{References}

1. Peggs KS, Quezada SA, Chambers CA, Korman AJ, Allison JP. Blockade of CTLA- 4 on both effector and regulatory T cell compartments contributes to the antitumor activity of anti-CTLA-4 antibodies. J Exp Med. 2009; 206: 1717-25.

2. Tumeh PC, Harview CL, Yearley JH, et al. PD-1 blockade induces responses by inhibiting adaptive immune resistance. Nature. 2014; 515: 568-71.

3. Hodi FS, O'Day SJ, McDermott DF, et al. Improved survival with ipilimumab in patients with metastatic melanoma. N Engl J Med. 2010; 363: 711-23.

4. Anagnostou VK, Brahmer JR. Cancer Immunotherapy: A Future Paradigm Shift in the Treatment of Non-Small Cell Lung Cancer. Clin Cancer Res. 2015; 21: 976-84.

5. Lee DW, Kochenderfer JN, Stetler-Stevenson M, et al. T cells expressing CD19 chimeric antigen receptors for acute lymphoblastic leukaemia in children and young adults: a phase 1 dose-escalation trial. The Lancet. 2015; 385: 517-28.

6. Rosenberg SA, Restifo NP. Adoptive cell transfer as personalized immunotherapy for human cancer. Science. 2015; 348: 62-8.

7. Ye B, Stary CM, Gao Q, et al. Genetically Modified T-Cell-Based Adoptive Immunotherapy in Hematological Malignancies. J Immunol Res. 2017; 2017: 5210459.

8. Rosenberg SA, Packard BS, Aebersold PM, et al. Use of Tumor-Infiltrating Lymphocytes and Interleukin-2 in the Immunotherapy of Patients with Metastatic Melanoma. N Engl J Med. 1988; 319: 1676-80.

9. Brentjens RJ, Davila ML, Riviere I, et al. CD19-Targeted T Cells Rapidly Induce Molecular Remissions in Adults with Chemotherapy-Refractory Acute Lymphoblastic Leukemia. Science Translational Medicine. 2013; 5: 177ra38-177ra38.

10. Raje N, Berdeja J, Lin Y, et al. Anti-BCMA CAR T-Cell Therapy bb2121 in Relapsed or Refractory Multiple Myeloma. New England Journal of Medicine. 2019; 380: 1726-37.

11. Tang X, Yang L, Li Z, et al. First-in-man clinical trial of CAR NK-92 cells: safety test of CD33-CAR NK-92 cells in patients with relapsed and refractory acute myeloid leukemia. Am J Cancer Res. 2018; 8: 1083-9.

12. Klichinsky M, Ruella M, Shestova O, et al. Human chimeric antigen receptor macrophages for cancer immunotherapy. Nat Biotechnol [Internet]. 2020 [cited 1 April 2020]; Available at: http://www.nature.com/articles/s41587-0200462-y.

13. Ribas A, Wolchok JD. Cancer immunotherapy using checkpoint blockade. Science. 2018; 359: 1350-5.

14. Johnson DB, Balko JM, Compton ML, et al. Fulminant Myocarditis with Combination Immune Checkpoint Blockade. N Engl J Med. 2016; 375: 1749-55.

15. Marthey L, Mateus C, Mussini C, et al. Cancer Immunotherapy with AntiCTLA-4 Monoclonal Antibodies Induces an Inflammatory Bowel Disease. ECCOJC. 2016; 10: 395-401.

16. Mahmoud SMA, Paish EC, Powe DG, et al. Tumor-Infiltrating CD8 ${ }^{+}$ Lymphocytes Predict Clinical Outcome in Breast Cancer. JCO. 2011; 29: 1949-55.

17. Ji R-R, Chasalow SD, Wang L, et al. An immune-active tumor microenvironment favors clinical response to ipilimumab. Cancer Immunol Immunother. 2012; 61: 1019-31.

18. Swanton C. Intratumor Heterogeneity: Evolution through Space and Time. Cancer Res. 2012; 72: 4875-82.

19. Gerlinger M, Rowan AJ, Horswell $S$, et al. Intratumor Heterogeneity and Branched Evolution Revealed by Multiregion Sequencing. New England Journal of Medicine. 2012; 366: 883-92.

20. Dijkers EC, Oude Munnink TH, Kosterink JG, et al. Biodistribution of 89Zr-trastuzumab and PET Imaging of HER2-Positive Lesions in Patients With Metastatic Breast Cancer. Clin Pharmacol Ther. 2010; 87: 586-92.

21. Almuhaideb A, Papathanasiou N, Bomanji J. ${ }^{18}$ F-FDG PET/CT Imaging In Oncology. Annals of Saudi Medicine. 2011; 31: 3-13.

22. Love $\mathrm{C}$, Tomas MB, Tronco GG, Palestro CJ. FDG PET of infection and inflammation. Radiographics. 2005; 25: 1357-68.

23. Rashidian M, Ingram JR, Dougan M, et al. Predicting the response to CTLA-4 blockade by longitudinal noninvasive monitoring of CD8 T cells. Journal of Experimental Medicine. 2017; 214: 2243-55.

24. Tavaré R, McCracken MN, Zettlitz KA, et al. Engineered antibody fragments for immuno-PET imaging of endogenous CD8+ T cells in vivo. PNAS. 2014; 111: 1108-13.

25. van Dongen GAMS, Visser GWM, Lub-de Hooge MN, de Vries EG, Perk LR. Immuno-PET: a navigator in monoclonal antibody development and applications. Oncologist. 2007; 12: 1379-89.

26. Pittet MJ, Grimm J, Berger CR, et al. In vivo imaging of $\mathrm{T}$ cell delivery to tumors after adoptive transfer therapy. Proceedings of the National Academy of Sciences. 2007; 104: 12457-61.

27. Keu KV, Witney TH, Yaghoubi S, et al. Reporter Gene Imaging of Targeted T-Cell Immunotherapy in Recurrent Glioma. Sci Transl Med. 2017; 9: eaag2196. 
28. Gibson HM, McKnight BN, Malysa A, et al. IFNY PET Imaging as a Predictive Tool for Monitoring Response to Tumor Immunotherapy. Cancer Res. 2018; 78: 5706-17.

29. Li J, Van Valkenburgh J, Hong X, Conti PS, Zhang X, Chen K. Small molecules as theranostic agents in cancer immunology. Theranostics. 2019; 9: 7849-71.

30. Nabi HA, Zubeldia JM. Clinical Applications of 18F-FDG in Oncology. J Nucl Med Technol. 2002; 30: 3-9.

31. Kelloff GJ, Hoffman JM, Johnson B, et al. Progress and promise of FDG-PET imaging for cancer patient management and oncologic drug development. Clin Cancer Res. 2005; 11: 2785-808

32. Iravani A, Hicks RJ. Imaging the cancer immune environment and its response to pharmacological intervention- Part 1- The role of FDG PET/CT. J Nucl Med. 2020; jnumed.119.234278

33. Kaira K, Serizawa M, Koh Y, et al. Relationship between 18F-FDG uptake on positron emission tomography and molecular biology in malignant pleural mesothelioma. European Journal of Cancer. 2012; 48: 1244-54.

34. Khandani AH, Dunphy $\mathrm{CH}$, Meteesatien P, Dufault DL, Ivanovic M, Shea TC. Glut1 and Glut3 expression in lymphoma and their association with tumor intensity on 18F-fluorodeoxyglucose positron emission tomography. Nuclear Medicine Communications. 2009; 30: 594-601.

35. Waarde A van, Cobben DCP, Suurmeijer AJH, et al. Selectivity of 18F-FLT and 18F-FDG for Differentiating Tumor from Inflammation in a Rodent Model. J Nucl Med. 2004; 45: 695-700.

36. Barthel H, Cleij MC, Collingridge DR, et al. 3'-Deoxy-3'-[18F]Fluorothymidine as a New Marker for Monitoring Tumor Response to Antiproliferative Therapy in vivo with Positron Emission Tomography. Cancer Res. 2003; 63: 3791-8.

37. Schelhaas S, Heinzmann K, Bollineni VR, et al. Preclinical Applications of

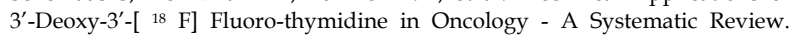
Theranostics. 2017; 7: 40-50.

38. Griffith DA, Jarvis SM. Nucleoside and nucleobase transport systems of mammalian cells. Biochim Biophys Acta. 1996; 1286: 153-81.

39. Arnér ESJ, Flygar M, Bohman C, Wallstrom B, Eriksson S. Deoxycytidine kinase is constitutively expressed in human lymphocytes: Consequences for compartmentation effects, unscheduled dna synthesis, and viral replication in resting cells. Experimental Cell Research. 1988; 178: 335-42.

40. Radu CG, Shu CJ, Nair-Gill E, et al. Molecular imaging of lymphoid organs and immune activation by positron emission tomography with a new [18F]-labeled 2'-deoxycytidine analog. Nat Med. 2008; 14: 783-8.

41. Schwarzenberg J, Radu CG, Benz M, et al. Human biodistribution and radiation dosimetry of novel PET probes targeting the deoxyribonucleoside salvage pathway. Eur J Nucl Med Mol Imaging. 2011; 38: 711-21.

42. Kim W, Le TM, Wei L, et al. [18F]CFA as a clinically translatable probe for PET imaging of deoxycytidine kinase activity. PNAS. 2016; 113: 4027-32.

43. Antonios JP, Soto H, Everson RG, et al. Detection of immune responses after immunotherapy in glioblastoma using PET and MRI. PNAS. 2017; 114: 10220-5.

44. Roecker AM, Stockert A, Kisor DF. Nelarabine in the treatment of refractory T-cell malignancies. Clin Med Insights Oncol. 2010; 4: 133-41.

45. Namavari M, Chang Y-F, Kusler B, Yaghoubi S, Mitchell BS, Gambhir SS. Synthesis of 2 '-deoxy-2'-[18F]fluoro-9- $\beta$-D-arabinofuranosylguanine: a novel agent for imaging T-cell activation with PET. Mol Imaging Biol. 2011; 13: 812-8.

46. Levi J, Lam T, Goth SR, et al. Imaging of activated T cells as an early predictor of immune response to anti-PD-1 therapy. Cancer Res. 2019; 3455-65.

47. Ronald JA, Kim B-S, Gowrishankar G, et al. A PET Imaging Strategy to Visualize Activated T Cells in Acute Graft-versus-Host Disease Elicited by Allogenic Hematopoietic Cell Transplant. Cancer Res. 2017; 77: 2893-902.

48. Yan Y, Zhang G-X, Gran B, et al. IDO Upregulates Regulatory T Cells via Tryptophan Catabolite and Suppresses Encephalitogenic T Cell Responses in Experimental Autoimmune Encephalomyelitis. The Journal of Immunology. 2010; 185: 5953-61.

49. Fallarino F, Grohmann U, Vacca C, et al. T cell apoptosis by tryptophan catabolism. Cell Death Differ. 2002; 9: 1069-77.

50. Mantovani A, Schioppa T, Porta C, Allavena P, Sica A. Role of tumor-associated macrophages in tumor progression and invasion. Cancer Metastasis Rev. 2006; 25: 315-22.

51. Okamoto A, Nikaido T, Ochiai K, et al. Indoleamine 2,3-Dioxygenase Serves as a Marker of Poor Prognosis in Gene Expression Profiles of Serous Ovarian Cancer Cells. Clin Cancer Res. 2005; 11: 6030-9.

52. Xin Y, Cai H. Improved Radiosynthesis and Biological Evaluations of L- and D-1-[18F]Fluoroethyl-Tryptophan for PET Imaging of IDO-Mediated Kynurenine Pathway of Tryptophan Metabolism. Mol Imaging Biol. 2017; 19: 589-98.

53. Larimer BM, Wehrenberg-Klee E, Dubois F, et al. Granzyme B PET Imaging as a Predictive Biomarker of Immunotherapy Response. Cancer Res. 2017; 77: 2318-27.

54. Meyer J-P, Houghton JL, Kozlowski P, et al. 18F-Based Pretargeted PET Imaging Based on Bioorthogonal Diels-Alder Click Chemistry. Bioconjug Chem. 2016; 27: 298-301.

55. Zeglis BM, Sevak KK, Reiner T, et al. A Pretargeted PET Imaging Strategy Based on Bioorthogonal Diels-Alder Click Chemistry. J Nucl Med. 2013; 54: 1389-96.

56. Song IH, Lee TS, Park YS, et al. Immuno-PET Imaging and Radioimmunotherapy of 64Cu-/177Lu-Labeled Anti-EGFR Antibody in Esophageal Squamous Cell Carcinoma Model. J Nucl Med. 2016; 57: 1105-11.
57. Gebhart G, Lamberts LE, Wimana Z et al. Molecular imaging as a tool to investigate heterogeneity of advanced HER2-positive breast cancer and to predict patient outcome under trastuzumab emtansine (T-DM1): the ZEPHIR trial. Ann Oncol. 2016; 27: 619-24.

58. Cekic C, Day Y-J, Sag D, Linden J. Myeloid Expression of Adenosine A2A Receptor Suppresses T and NK Cell Responses in the Solid Tumor Microenvironment. Cancer Res. 2014; 74: 7250-9.

59. Chanmee T, Ontong P, Konno K, Itano N. Tumor-Associated Macrophages as Major Players in the Tumor Microenvironment. Cancers. 2014; 6: 1670-90.

60. Movahedi K, Schoonooghe S, Laoui D, et al. Nanobody-Based Targeting of the Macrophage Mannose Receptor for Effective In vivo Imaging of Tumor-Associated Macrophages. Cancer Res. 2012; 72: 4165-77.

61. Blykers A, Schoonooghe S, Xavier C, et al. PET Imaging of Macrophage Mannose Receptor-Expressing Macrophages in Tumor Stroma Using 18F-Radiolabeled Camelid Single-Domain Antibody Fragments. J Nucl Med. 2015; 56: 1265-71

62. Xavier C, Blykers A, Laoui D, et al. Clinical Translation of [68Ga]Ga-NOTA-anti-MMR-sdAb for PET/CT Imaging of Protumorigenic Macrophages. Mol Imaging Biol. 2019; 21: 898-906.

63. Cheng D, Zou W, Li X, et al. Preparation and Evaluation of 99m Tc-labeled anti-CD11b Antibody Targeting Inflammatory Microenvironment for Colon Cancer Imaging. Chem Biol Drug Des. 2015; 85: 696-701.

64. Rashidian M, Keliher EJ, Dougan M, et al. Use of 18F-2-Fluorodeoxyglucose to Label Antibody Fragments for Immuno-Positron Emission Tomography of Pancreatic Cancer. ACS Cent Sci. 2015; 1: 142-7.

65. Rashidian M, Keliher EJ, Bilate AM, et al. Noninvasive imaging of immune responses. Proc Natl Acad Sci USA. 2015; 112: 6146-51.

66. Elssen CHMJV, Rashidian M, Vrbanac V, et al. Noninvasive Imaging of Human Immune Responses in a Human Xenograft Model of Graft-VersusHost Disease. J Nucl Med. 2017; 58: 1003-8.

67. Groeve KD, Deschacht N, Koninck CD, et al. Nanobodies as Tools for In vivo Imaging of Specific Immune Cell Types. J Nucl Med. 2010; 51: 782-9.

68. Shaffer TM, Aalipour A, Schürch CM, Gambhir SS. PET Imaging of the Natural Killer Cell Activation Receptor NKp30. J Nucl Med. 2020; 61: 1348-54.

69. Meier R, Piert M, Piontek G, et al. Tracking of [18F]FDG-labeled natural killer cells to HER2/neu-positive tumors. Nucl Med Biol. 2008; 35: 579-88.

70. Melder RJ, Brownell AL, Shoup TM, Brownell GL, Jain RK. Imaging of activated natural killer cells in mice by positron emission tomography: preferential uptake in tumors. Cancer Res. 1993; 53: 5867-71.

71. Matsushita H, Vesely MD, Koboldt DC, et al. Cancer exome analysis reveals a T-cell-dependent mechanism of cancer immunoediting. Nature. 2012; 482: 400-4.

72. Alspach E, Lussier DM, Miceli AP, et al. MHC-II neoantigens shape tumour immunity and response to immunotherapy. Nature. 2019; 574: 696-701.

73. Beckford Vera DR, Smith CC, Bixby LM, et al. Immuno-PET imaging of tumor-infiltrating lymphocytes using zirconium-89 radiolabeled anti-CD3 antibody in immune-competent mice bearing syngeneic tumors. PLoS One. 2018; $13: 1-19$

74. Freise AC, Zettlitz KA, Salazar FB, Lu X, Tavaré R, Wu AM. ImmunoPET Imaging of Murine CD4+ T Cells Using Anti-CD4 Cys-Diabody: Effects of Protein Dose on T Cell Function and Imaging. Mol Imaging Biol. 2017; 19: $599-609$

75. Larimer BM, Wehrenberg-Klee E, Caraballo A, Mahmood U. Quantitative CD3 PET Imaging Predicts Tumor Growth Response to Anti-CTLA-4 Therapy. J Nucl Med. 2016; 57: 1607-11.

76. Tavaré R, Escuin-Ordinas H, Mok S, et al. An Effective Immuno-PET Imaging Method to Monitor CD8-Dependent Responses to Immunotherapy. Cancer Res. 2016; 76: 73-82.

77. Dranoff G, Jaffee E, Lazenby A, et al. Vaccination with irradiated tumor cells engineered to secrete murine granulocyte-macrophage colony-stimulating factor stimulates potent, specific, and long-lasting anti-tumor immunity. Proc Natl Acad Sci USA. 1993; 90: 3539-43.

78. Rashidian M, LaFleur MW, Verschoor VL, et al. Immuno-PET identifies the myeloid compartment as a key contributor to the outcome of the antitumor response under PD-1 blockade. Proc Natl Acad Sci USA. 2019; 116: 16971-80.

79. Pandit-Taskar N, Postow MA, Hellmann MD, et al. First-in-Humans Imaging with 89 Zr-Df-IAB22M2C Anti-CD8 Minibody in Patients with Solid Malignancies: Preliminary Pharmacokinetics, Biodistribution, and Lesion Targeting. J Nucl Med. 2020; 61: 512-9.

80. Coyle AJ, Lehar S, Lloyd C, et al. The CD28-Related Molecule ICOS Is Required for Effective T Cell-Dependent Immune Responses. Immunity. 2000; 13: $95-105$

81. Rogers PR, Song J, Gramaglia I, Killeen N, Croft M. OX40 Promotes Bcl-xL and Bcl-2 Expression and Is Essential for Long-Term Survival of CD4 T Cells. Immunity. 2001; 15: 445-55.

82. DeBenedette MA, Shahinian A, Mak TW, Watts TH. Costimulation of CD28- T lymphocytes by 4-1BB ligand. The Journal of Immunology. 1997; 158: 551-9.

83. Xiao Z, Mayer AT, Nobashi TW, Gambhir SS. ICOS is an indicator of T cell-mediated response to cancer immunotherapy. Cancer Res. 2020; 3023-32.

84. Alam IS, Mayer AT, Sagiv-Barfi I, et al. Imaging activated T cells predicts response to cancer vaccines. J Clin Invest. 2018; 128: 2569-80.

85. Gubin MM, Zhang X, Schuster $H$, et al. Checkpoint blockade cancer immunotherapy targets tumour-specific mutant antigens. Nature. 2014; 515: $577-81$. 
86. Alspach E, Lussier DM, Miceli AP, et al. MHC-II neoantigens shape tumour immunity and response to immunotherapy. Nature. 2019; 574: 696-701.

87. Woodham AW, Zeigler SH, Zeyang EL, et al. In vivo detection of antigenspecific CD8+ $\mathrm{T}$ cells by immuno-positron emission tomography. Nat Methods [Internet]. 2020 [cited 21 September 2020]; Available at: http://www. nature.com/articles/s41592-020-0934-5.

88. Dranoff G. Cytokines in cancer pathogenesis and cancer therapy. Nat Rev Cancer. 2004; 4: 11-22.

89. Landskron G, De la Fuente M, Thuwajit P, Thuwajit C, Hermoso MA. Chronic Inflammation and Cytokines in the Tumor Microenvironment. Journal of Immunology Research. 2014; 2014: 1-19.

90. Cao Q, Cai W, Li Z-B, et al. PET imaging of acute and chronic inflammation in living mice. Eur J Nucl Med Mol Imaging. 2007; 34: 1832-42.

91. Hollander MW den, Bensch F, Glaudemans AWJM, et al. TGF- $\beta$ Antibody Uptake in Recurrent High-Grade Glioma Imaged with 89Zr-Fresolimumab PET. J Nucl Med. 2015; 56: 1310-4.

92. Hartimath SV, Draghiciu O, van de Wall S, et al. Noninvasive monitoring of cancer therapy induced activated T cells using [18F]FB-IL-2 PET imaging. Oncoimmunology. 2017; 6: e1248014.

93. Veen EL van der, Suurs FV, Cleeren F, et al. Development and evaluation of interleukin-2 derived radiotracers for PET imaging of T-cells in mice. J Nucl Med. 2020; jnumed.119.238782.

94. Sharma A, Subudhi SK, Blando J, et al. Anti-CTLA-4 Immunotherapy Does Not Deplete FOXP3 + Regulatory T Cells (Tregs) in Human Cancers. Clin Cancer Res. 2019; 25: 1233-8.

95. Wei SC, Duffy CR, Allison JP. Fundamental Mechanisms of Immune Checkpoint Blockade Therapy. Cancer Discov. 2018; 8: 1069-86.

96. Du Y, Jin Y, Sun W, Fang J, Zheng J, Tian J. Advances in molecular imaging of immune checkpoint targets in malignancies: current and future prospect. Eur Radiol. 2019; 29: 4294-302.

97. Davis AA, Patel VG. The role of PD-L1 expression as a predictive biomarker: an analysis of all US Food and Drug Administration (FDA) approvals of immune checkpoint inhibitors. Journal for ImmunoTherapy of Cancer. 2019; 7: 278.

98. Sakane $\mathrm{T}$, Murase $\mathrm{T}$, Okuda $\mathrm{K}$, et al. A comparative study of PD-L1 immunohistochemical assays with four reliable antibodies in thymic carcinoma. Oncotarget. 2018; 9: 6993-7009.

99. Hunter KA, Socinski MA, Villaruz LC. PD-L1 Testing in Guiding Patient Selection for PD-1/PD-L1 Inhibitor Therapy in Lung Cancer. Mol Diagn Ther. 2018; $22: 1-10$.

100. Hettich M, Braun F, Bartholomä MD, Schirmbeck R, Niedermann G. High-Resolution PET Imaging with Therapeutic Antibody-based PD-1/PD-L1 Checkpoint Tracers. Theranostics. 2016; 6: 1629-40.

101. Dovedi SJ, Adlard AL, Lipowska-Bhalla G, et al. Acquired resistance to fractionated radiotherapy can be overcome by concurrent PD-L1 blockade. Cancer Res. 2014; 74: 5458-68

102. Manukian G, Bar-Ad V, Lu B, Argiris A, Johnson JM. Combining Radiation and Immune Checkpoint Blockade in the Treatment of Head and Neck Squamous Cell Carcinoma. Front Oncol. 2019; 9: 1-14.

103. Kikuchi M, Clump DA, Srivastava RM, et al. Preclinical immunoPET/CT imaging using Zr-89-labeled anti-PD-L1 monoclonal antibody for assessing radiation-induced PD-L1 upregulation in head and neck cancer and melanoma. OncoImmunology. 2017; 6: e1329071.

104. Lv G, Sun X, Qiu L, et al. PET Imaging of Tumor PD-L1 Expression with a Highly Specific Nonblocking Single-Domain Antibody. J Nucl Med. 2020; 61: $117-22$

105. Ingram JR, Dougan M, Rashidian M, et al. PD-L1 is an activation-independent marker of brown adipocytes. Nat Commun. 2017; 8: 1-10.

106. Broos K, Keyaerts M, Lecocq Q, et al. Non-invasive assessment of murine PD-L1 levels in syngeneic tumor models by nuclear imaging with nanobody tracers. Oncotarget. 2017; 8: 41932-46.

107. Broos K, Lecocq Q, Xavier C, et al. Evaluating a Single Domain Antibody Targeting Human PD-L1 as a Nuclear Imaging and Therapeutic Agent. Cancers (Basel). 2019; 11: 1-19.

108. Trotter DEG, Meng $X$, McQuade $P$, et al. In vivo Imaging of the Programmed Death Ligand 1 by 18F PET. J Nucl Med. 2017; 58: 1852-7.

109. Chatterjee S, Lesniak WG, Miller MS, et al. Rapid PD-L1 detection in tumors with PET using a highly specific peptide. Biochemical and Biophysical Research Communications. 2017; 483: 258-63.

110. Chatterjee S, Lesniak WG, Gabrielson M, et al. A humanized antibody for imaging immune checkpoint ligand PD-L1 expression in tumors. Oncotarget. 2016; 7: 10215-27.

111. Lesniak WG, Chatterjee S, Gabrielson M, et al. PD-L1 Detection in Tumors Using [64Cu]Atezolizumab with PET. Bioconjugate Chem. 2016; 27: 2103-10.

112. Bensch F, van der Veen EL, Lub-de Hooge MN, et al. 89 Zr-atezolizumab imaging as a non-invasive approach to assess clinical response to PD-L1 blockade in cancer. Nature Medicine. 2018; 24: 1852-8.

113. Jagoda EM, Vasalatiy $\mathrm{O}$, Basuli $\mathrm{F}$, et al. Immuno-PET Imaging of the Programmed Cell Death-1 Ligand (PD-L1) Using a Zirconium-89 Labeled Therapeutic Antibody, Avelumab. Mol Imaging. 2019; 18: 1536012119829986.

114. Giesen D, Broer LN, Hooge MNL, et al. Probody Therapeutic Design of 89ZrCX-072 Promotes Accumulation in PD-L1-Expressing Tumors Compared to Normal Murine Lymphoid Tissue. Clin Cancer Res. 2020; 26: 3999-4009.
115. Erster O, Thomas JM, Hamzah J, et al. Site-specific targeting of antibody activity in vivo mediated by disease-associated proteases. Journal of Controlled Release. 2012; 161: 804-12.

116. Desnoyers LR, Vasiljeva O, Richardson JH, et al. Tumor-Specific Activation of an EGFR-Targeting Probody Enhances Therapeutic Index. Science Translational Medicine. 2013; 5: 207ra144-207ra144.

117. Lipovšek D. Adnectins: engineered target-binding protein therapeutics. Protein Eng Des Sel. 2011; 24: 3-9.

118. Natarajan A, Patel CB, Ramakrishnan S, Panesar PS, Long SR, Gambhir SS. A Novel Engineered Small Protein for Positron Emission Tomography Imaging of Human Programmed Death Ligand-1: Validation in Mouse Models and Human Cancer Tissues. Clin Cancer Res. 2019; 25: 1774-85.

119. Donnelly DJ, Smith RA, Morin P, et al. Synthesis and Biologic Evaluation of a Novel 18F-Labeled Adnectin as a PET Radioligand for Imaging PD-L1 Expression. J Nucl Med. 2018; 59: 529-35.

120. Niemeijer AN, Leung D, Huisman MC, et al. Whole body PD-1 and PD-L1 positron emission tomography in patients with non-small-cell lung cancer. Nature Communications. 2018; 9: 1-5

121. Mellman I, Coukos G, Dranoff G. Cancer immunotherapy comes of age. Nature. 2011; 480: 480-9.

122. Wu X, Gu Z, Chen Y, et al. Application of PD-1 Blockade in Cancer Immunotherapy. Comput Struct Biotechnol J. 2019; 17: 661-74

123. Natarajan A, Mayer AT, Xu L, Reeves RE, Gano J, Gambhir SS. Novel Radiotracer for ImmunoPET Imaging of PD-1 Checkpoint Expression on Tumor Infiltrating Lymphocytes. Bioconjugate Chem. 2015; 26: 2062-9.

124. England CG, Ehlerding EB, Hernandez R, et al. Preclinical Pharmacokinetics and Biodistribution Studies of $89 \mathrm{Zr}$-Labeled Pembrolizumab. J Nucl Med. 2017; 58: 162-8.

125. Hayashi T. Dysfunction of Lacrimal and Salivary Glands in Sjögren's Syndrome: Nonimmunologic Injury in Preinflammatory Phase and Mouse Model. J Biomed Biotechnol. 2011; 2011: 1-15.

126. Natarajan A, Mayer AT, Reeves RE, Nagamine CM, Gambhir SS. Development of Novel ImmunoPET Tracers to Image Human PD-1 Checkpoint Expression on Tumor-Infiltrating Lymphocytes in a Humanized Mouse Model. Mol Imaging Biol. 2017; 19: 903-14.

127. England CG, Jiang D, Ehlerding EB, et al. 89Zr-labeled nivolumab for imaging of T-cell infiltration in a humanized murine model of lung cancer. Eur J Nucl Med Mol Imaging. 2018; 45: 110-20.

128. Thibult M-L, Mamessier E, Gertner-Dardenne J, et al. PD-1 is a novel regulator of human B-cell activation. Int Immunol. 2013; 25: 129-37.

129. Gordon SR, Maute RL, Dulken BW, et al. PD-1 expression by tumourassociated macrophages inhibits phagocytosis and tumour immunity. Nature. 2017; 545: 495-9

130. Walker LSK. Treg and CTLA-4: Two intertwining pathways to immune tolerance. J Autoimmun. 2013; 45: 49-57.

131. Weber JS, Kähler KC, Hauschild A. Management of Immune-Related Adverse Events and Kinetics of Response With Ipilimumab. JCO. 2012; 30: 2691-7.

132. Allen EMV, Miao D, Schilling B, et al. Genomic correlates of response to CTLA-4 blockade in metastatic melanoma. Science. 2015; 350: 207-11.

133. Salvi S, Fontana V, Boccardo S, et al. Evaluation of CTLA-4 expression and relevance as a novel prognostic factor in patients with non-small cell lung cancer. Cancer Immunol Immunother. 2012; 61: 1463-72.

134. Higashikawa K, Yagi K, Watanabe K, et al. 64Cu-DOTA-Anti-CTLA-4 mAb Enabled PET Visualization of CTLA-4 on the T-Cell Infiltrating Tumor Tissues. PLOS ONE. 2014; 9; e109866.

135. Ehlerding EB, Lee HJ, Jiang D, et al. Antibody and fragment-based PET imaging of CTLA-4+ T-cells in humanized mouse models. Am J Cancer Res. 2019; 9: 53-63

136. Camacho LH. CTLA-4 blockade with ipilimumab: biology, safety, efficacy, and future considerations. Cancer Med. 2015; 4: 661-72.

137. Andrews LP, Marciscano AE, Drake CG, Vignali DAA. LAG3 (CD223) as a cancer immunotherapy target. Immunological Reviews. 2017; 276: 80-96.

138. Lecocq Q, Zeven K, De Vlaeminck Y, et al. Noninvasive Imaging of the Immune Checkpoint LAG-3 Using Nanobodies, from Development to PreClinical Use. Biomolecules. 2019:9.

139. Park JH, Rivière I, Gonen M, et al. Long-Term Follow-up of CD19 CAR Therapy in Acute Lymphoblastic Leukemia. New England Journal of Medicine. 2018; 378: 449-59.

140. Schuster SJ, Svoboda J, Chong EA, et al. Chimeric Antigen Receptor T Cells in Refractory B-Cell Lymphomas. New England Journal of Medicine. 2017; 377: 2545-54.

141. Sadelain M, Brentjens $R$, Rivière I. The promise and potential pitfalls of chimeric antigen receptors. Current Opinion in Immunology. 2009; 21: 215-23.

142. Teachey DT, Lacey SF, Shaw PA, et al. Identification of Predictive Biomarkers for Cytokine Release Syndrome after Chimeric Antigen Receptor T-cell Therapy for Acute Lymphoblastic Leukemia. Cancer Discov. 2016; 6: 664-79.

143. Fehse B, Badbaran A, Berger C, et al. Digital PCR Assays for Precise Quantification of CD19-CAR-T Cells after Treatment with Axicabtagene Ciloleucel. Molecular Therapy - Methods \& Clinical Development. 2020; 16: $172-8$

144. Zheng Z, Chinnasamy N, Morgan RA. Protein L: a novel reagent for the detection of Chimeric Antigen Receptor (CAR) expression by flow cytometry. Journal of Translational Medicine. 2012; 10: 29. 
145. Kircher MF, Allport JR, Graves EE, et al. In vivo High Resolution Three-Dimensional Imaging of Antigen-Specific Cytotoxic T-Lymphocyte Trafficking to Tumors. Cancer Res. 2003; 63: 6838-46.

146. Kircher MF, Gambhir SS, Grimm J. Noninvasive cell-tracking methods. Nature Reviews Clinical Oncology. 2011; 8: 677-88.

147. Papierniak CK, Bourey RE, Kretschmer RR, Gotoff SP, Colombetti LG. Technetium-99m Labeling of Human Monocytes for Chemotactic Studies. J Nucl Med. 1976; 17: 988-92.

148. Weist MR, Starr R, Aguilar B, et al. PET of Adoptively Transferred Chimeric Antigen Receptor T Cells with 89Zr-Oxine. J Nucl Med. 2018; 59: 1531-7.

149. Bansal A, Pandey MK, Demirhan YE, et al. Novel 89Zr cell labeling approach for PET-based cell trafficking studies. EJNMMI Research. 2015; 5: 19.

150. Lee SH, Soh H, Chung JH, et al. Feasibility of real-time in vivo 89Zr-DFOlabeled CAR T-cell trafficking using PET imaging. Hagemeyer CE, Ed. PLoS ONE. 2020; 15: 1-21.

151. Griessinger CM, Maurer A, Kesenheimer C, et al. $64 \mathrm{Cu}$ antibody-targeting of the T-cell receptor and subsequent internalization enables in vivo tracking of lymphocytes by PET. PNAS. 2015; 112: 1161-6.

152. Yaghoubi SS, Campbell DO, Radu CG, Czernin J. Positron Emission Tomography Reporter Genes and Reporter Probes: Gene and Cell Therapy Applications. Theranostics. 2012; 2: 374-91.

153. Gambhir SS, Bauer E, Black ME, et al. A mutant herpes simplex virus type 1 thymidine kinase reporter gene shows improved sensitivity for imaging reporter gene expression with positron emission tomography. PNAS. 2000; 97: 2785-90

154. Yaghoubi SS, Jensen MC, Satyamurthy N, et al. Noninvasive detection of therapeutic cytolytic T cells with 18 F-FHBG PET in a patient with glioma. Nature Clinical Practice Oncology. 2009; 6: 53-8.

155. Brown CE, Alizadeh D, Starr R, et al. Regression of Glioblastoma after Chimeric Antigen Receptor T-Cell Therapy. N Engl J Med. 2016; 375: 2561-9.

156. Keu KV, Witney TH, Yaghoubi S, et al. Reporter Gene Imaging of Targeted T-Cell Immunotherapy in Recurrent Glioma. Sci Transl Med. 2017; 9: 1-25.

157. Maury S, Rosenzwajg M, Redjoul R, et al. Lymphodepletion followed by infusion of suicide gene-transduced donor lymphocytes to safely enhance their antitumor effect: a phase I/II study. Leukemia. 2014; 28 : 2406-10.

158. Emami-Shahri N, Foster J, Kashani R, et al. Clinically compliant spatial and temporal imaging of chimeric antigen receptor T-cells. Nature Communications. 2018; 9: 1-12.

159. Doubrovin MM, Doubrovina ES, Zanzonico P, Sadelain M, Larson SM, O'Reilly RJ. In vivo Imaging and Quantitation of Adoptively Transferred Human Antigen-Specific $\mathrm{T}$ Cells Transduced to Express a Human Norepinephrine Transporter Gene. Cancer Res. 2007; 67: 11959-69.

160. Vedvyas Y, Shevlin E, Zaman M, et al. Longitudinal PET imaging demonstrates biphasic CAR T cell responses in survivors. JCI Insight. 1: 1-17.

161. Penheiter AR, Russell SJ, Carlson SK. The Sodium Iodide Symporter (NIS) as an Imaging Reporter for Gene, Viral, and Cell-based Therapies. Curr Gene Ther. 2012; 12: 33-47.

162. Wapnir IL, van de Rijn M, Nowels K, et al. Immunohistochemical Profile of the Sodium/Iodide Symporter in Thyroid, Breast, and Other Carcinomas Using High Density Tissue Microarrays and Conventional Sections. J Clin Endocrinol Metab. 2003; 88: 1880-8.

163. Zhang H, Moroz MA, Serganova I, et al. Imaging Expression of the Human Somatostatin Receptor Subtype-2 Reporter Gene with 68Ga-DOTATOC. J Nucl Med. 2011; 52: 123-31.

164. Barrio M, Czernin J, Fanti S, et al. The Impact of Somatostatin ReceptorDirected PET/CT on the Management of Patients with Neuroendocrine Tumor: A Systematic Review and Meta-Analysis. J Nucl Med. 2017; 58: 756-61.

165. Barsegian V, Hueben C, Mueller SP, et al. Impairment of lymphocyte function following yttrium-90 DOTATOC therapy. Cancer Immunol Immunother. 2015; 64: 755-64

166. Silver DA, Pellicer I, Fair WR, Heston WD, Cordon-Cardo C. Prostate-specific membrane antigen expression in normal and malignant human tissues. Clin Cancer Res. 1997; 3: 81-5.

167. Szabo Z, Mena E, Rowe SP, et al. Initial Evaluation of [18F]DCFPyL for Prostate-Specific Membrane Antigen (PSMA)-Targeted PET Imaging of Prostate Cancer. Mol Imaging Biol. 2015; 17: 565-74.

168. Minn I, Huss DJ, Ahn H-H, et al. Imaging CAR $\mathrm{T}$ cell therapy with PSMA-targeted positron emission tomography. Science Advances. 2019; 5: eaaw5096.

169. Daldrup-Link HE, Golovko D, Ruffell B, et al. MRI of Tumor-Associated Macrophages with Clinically Applicable Iron Oxide Nanoparticles. Clinical Cancer Research. 2011; 17: 5695-704.

170. Mohanty S, Yerneni K, Theruvath JL, et al. Nanoparticle enhanced MRI can monitor macrophage response to $\mathrm{CD} 47 \mathrm{mAb}$ immunotherapy in osteosarcoma. Cell Death Dis. 2019; 10:36.

171. Braisted AC, Oslob JD, Delano WL, et al. Discovery of a Potent Small Molecule IL-2 Inhibitor through Fragment Assembly. J Am Chem Soc. 2003; 125: 3714-5.

172. Thanos CD, Randal M, Wells JA. Potent Small-Molecule Binding to a Dynamic Hot Spot on IL-2. J Am Chem Soc. 2003; 125: 15280-1.

173. Xing Y, Chand G, Liu C, et al. Early Phase I Study of a 99mTc-Labeled AntiProgrammed Death Ligand-1 (PD-L1) Single-Domain Antibody in SPECT/CT Assessment of PD-L1 Expression in Non-Small Cell Lung Cancer. J Nucl Med. 2019; 60: 1213-20.

174. Kumar D, Lisok A, Dahmane E, et al. Peptide-based PET quantifies target engagement of PD-L1 therapeutics. J Clin Invest. 2019; 129: 616-30.
175. Wang W, Fliedner FP, Hansen AE, et al. Preclinical evaluation of cationic DOTA-triarginine-lipid conjugates for theranostic liquid brachytherapy. Nanotheranostics. 2020; 4: 142-55.

176. Wu W, Klockow JL, Mohanty S, et al. Theranostic nanoparticles enhance the response of glioblastomas to radiation. Nanotheranostics. 2019; 3: 299-310.

177. Cao Y, Wang J, Jiang Q-Y, et al. A Gold Nanoparticle Bouquet held on plasma membrane: An ultrasensitive dark-field imaging approach for Cancer Cell Analysis. 2020; 4: 9 .

178. Krebs S, Ahad A, Carter LM, et al. Antibody with Infinite Affinity for In vivo Tracking of Genetically Engineered Lymphocytes. J Nucl Med. 2018; 59: 1894-900.

179. Sellmyer MA, Richman SA, Lohith K, et al. Imaging CAR T Cell Trafficking with eDHFR as a PET Reporter Gene. Molecular Therapy. 2020; 28: 42-51.

180. Josefsson A, Nedrow JR, Park S, et al. Imaging, Biodistribution, and Dosimetry of Radionuclide-Labeled PD-L1 Antibody in an Immunocompetent Mouse Model of Breast Cancer. Cancer Res. 2016; 76: 472-9.

181. Nedrow JR, Josefsson A, Park S, Ranka S, Roy S, Sgouros G. Imaging of Programmed Cell Death Ligand 1: Impact of Protein Concentration on Distribution of Anti-PD-L1 SPECT Agents in an Immunocompetent Murine Model of Melanoma. J Nucl Med. 2017; 58: 1560-6.

182. De Silva RA, Kumar D, Lisok A, et al. Peptide-Based 68Ga-PET Radiotracer for Imaging PD-L1 Expression in Cancer. Mol Pharmaceutics. 2018; 15: 3946-52.

183. Lesniak WG, Mease RC, Chatterjee S, et al. Development of [18F]FPy-WL12 as a PD-L1 Specific PET Imaging Peptide. Mol Imaging. 2019; 18: 1536012119852189.

184. Lv G, Qiu L, Sun Y, et al. PET imaging of tumor PD-L1 expression with a highly specific non-blocking nanobody. J Nucl Med. 2019; jnumed.119.226712.

185. Maute RL, Gordon SR, Mayer AT, et al. Engineering high-affinity PD-1 variants for optimized immunotherapy and immuno-PET imaging. PNAS. 2015; 112: E6506-14.

186. Mayer AT, Natarajan A, Gordon SR, et al. Practical Immuno-PET Radiotracer Design Considerations for Human Immune Checkpoint Imaging. J Nucl Med. 2017; 58: 538-46

187. Wissler HL, Ehlerding EB, Lyu Z, et al. Site-Specific Immuno-PET Tracer to Image PD-L1. Mol Pharmaceutics. 2019; 16: 2028-36.

188. Chatterjee S, Lesniak WG, Nimmagadda S. Noninvasive Imaging of Immune Checkpoint Ligand PD-L1 in Tumors and Metastases for Guiding Immunotherapy. Mol Imaging. 2017; 16: 1-5.

189. Heskamp S, Hobo W, Molkenboer-Kuenen JDM, et al. Noninvasive Imaging of Tumor PD-L1 Expression Using Radiolabeled Anti-PD-L1 Antibodies. Cancer Res. 2015; 75: 2928-36.

190. Truillet C, Oh HLJ, Yeo SP, et al. Imaging PD-L1 Expression with ImmunoPET. Bioconjugate Chem. 2018; 29: 96-103.

191. Li D, Cheng S, Zou S, et al. Immuno-PET Imaging of 89Zr Labeled Anti-PD-L1 Domain Antibody. Mol Pharmaceutics. 2018; 15: 1674-81.

192. Li D, Zou S, Cheng S, Song S, Wang P, Zhu X. Monitoring the Response of PD-L1 Expression to Epidermal Growth Factor Receptor Tyrosine Kinase Inhibitors in Nonsmall-Cell Lung Cancer Xenografts by Immuno-PET Imaging. Mol Pharmaceutics. 2019; 16: 3469-76.

193. Stutvoet TS, Veen EL van der, Kol A, et al. Molecular imaging of PD-L1 expression and dynamics with the adnectin-based PET tracer 18F-BMS-986192. J Nucl Med. 2020; jnumed.119.241364.

194. Du Y, Liang X, Li Y, et al. Nuclear and Fluorescent Labeled PD-1-LiposomeDOX-64Cu/IRDye800CW Allows Improved Breast Tumor Targeted Imaging and Therapy. Mol Pharmaceutics. 2017; 14: 3978-86.

195. Natarajan A, Patel CB, Habte F, Gambhir SS. Dosimetry Prediction for Clinical Translation of $64 \mathrm{Cu}-\mathrm{Pembrolizumab}$ ImmunoPET Targeting Human PD-1 Expression. Sci Rep. 2018; 8: 1-11.

196. Ingram JR, Blomberg OS, Rashidian M, et al. Anti-CTLA-4 therapy requires an Fc domain for efficacy. PNAS. 2018; 115: 3912-7.

197. Ehlerding EB, England CG, Majewski RL, et al. ImmunoPET Imaging of CTLA-4 Expression in Mouse Models of Non-small Cell Lung Cancer. Mol Pharmaceutics. 2017; 14: 1782-9. 